\title{
Child Nutrition in India in the Nineties
}

\author{
Alessandro Tarozzi \\ Aprajit Mahajan \\ Duke University \\ Stanford University
}

April 2006*

\begin{abstract}
In this paper we use data from two independent cross-sectional surveys (completed in 199293 and 1998-99) to evaluate to what extent the rapid rates of growth observed during the 1990s has been associated with a reduction in malnutrition among very young children (age 0 to 3 ). We find that measures of short-term nutritional status based on weight given height show large improvements, especially in urban areas. Height-for-age, an indicator of long-term nutritional status, also shows improvements, but limited to urban areas. However, we also document that nutritional status improved substantially more for boys than for girls. The gender differences in the changes over time appear to be driven by states in North India, where the existence of widespread son preference has been documented by an immense body of research.
\end{abstract}

JEL: I12, J13, O53

Key words: Child Nutrition, India, Child Anthropometry

${ }^{*}$ We would like to thank Orazio Attanasio, Sonia Bhalotra, Angus Deaton, William Dow, Jean Drèze, Gayatri Koolwal, David McKenzie, Dilip Mookherjee and seminar participants at Boston University, Princeton University, RAND, the 2005 NEUDC conference (Brown University), the workshops "Indian Economy: Policy and Performance 1980-2000" (UBC) and "Human Development in India: Microdata Perspectives" (New Delhi) for useful comments. We are also very grateful to Macro International Inc. for granting us access to the data. Last but not least, Joanne Yoong provided excellent research assistance. We are solely responsible for all errors, and for all views expressed in this paper. Tarozzi (corresponding author), Department of Economics - Duke University, PO Box 90097, Durham, NC 27708, Email: taroz@econ.duke.edu. Mahajan: 579 Serra Mall, Stanford, CA 94305, Email: amahajan@stanford.edu. 


\section{Introduction}

India experienced several years of fast economic growth during the 1990s, and according to many observers this period also saw a considerable decline in poverty, especially in urban areas (see, for instance, Deaton (2003), Deaton and Drèze (2002), Tarozzi (2005)). ${ }^{1}$ This paper has three main objectives: first, we document to what extent the 1990s have seen a reduction in malnutrition among very young children (less than 3 years old); second, we study whether changes in child growth performance have been similar for boys and girls and in different geographical areas; third, we provide a first attempt at explaining the observed trends. The source of our data is the Indian National Family and Health Survey (NFHS), a data set that contains detailed information on health and fertility for two independent cross-sections of ever married women of fertility age, the first from 1992-93 and the second from 1998-99.

Many researchers have documented the presence in India of widespread child malnutrition, as measured by anthropometric indicators such as weight or height (e.g. Klasen (1999), Svedberg (2000)). The reduction of child malnutrition is certainly one of the most desirable components of economic development. Not only child malnutrition is strongly associated with increased child mortality and morbidity, but there is now ample evidence that inadequate nutrition in childhood (and in utero) hinders long term physical development, reduces the development of cognitive skills, and as a consequence affects negatively schooling attainment and several outcomes later in life, including productivity, mortality, and the likelihood of developing chronic diseases (see Strauss and Thomas (1998), Behrman, Alderman, and Hoddinott (2004) and Maluccio, Hoddinott, Behrman, Martorell, Quisumbing, and Stein (2005) for extensive references).

The analysis of gender differences plays a very important role in our analysis. Preference for sons over daughters and gender inequality are a well-known and still widespread reality in India, particularly in the North-West, and are reflected in phenomena such as sex-selective abortion and female disadvantage along crucial dimensions such as schooling, health and health care, and child mortality. Some studies also find gender differences in nutrient intakes and nutritional status (Behrman (1988a) and Behrman (1988b)), even if these findings are not confirmed in other studies, as discussed in Harriss (1995). Several studies from such different disciplines as Anthropology, Economics and Sociology have found that preference for sons is particularly strong in areas where the cultural, social, and economic role of women in society and/or within the household is weaker, for instance because women are less important as bread earners, dowries are more common, or bequests favor sons over daughters (see, e.g., Basu (1992), Dasgupta (1993), Miller (1981), Murthi, Guio, and Drèze (1995), Drèze and Sen (2002) for extensive references).

Many of the factors associated with gender inequality appear to be related to the presence of

\footnotetext{
${ }^{1}$ For a broad overview of the debate on poverty reduction in India over this period see the collected essays in Deaton and Kozel (2005), which also include less optimistic assessments of the degree of poverty reduction, as in Datt, Kozel, and Ravallion (2003) or Sen and Himanshu (2004).
} 
economic constraints. ${ }^{2}$ In a seminal paper, Rosenzweig and Schultz (1982) suggest that preferential treatment of boys may be an unfortunate but rational response to unequal economic "returns" to boys and girls, and hence can coexist with the absence of differences in the way the welfare of boys and girls enter the parents' utility function. The authors use this argument to explain the correlation between gender bias in survival rates and female labor market participation. Behrman (1988a) and Behrman (1988b), using data from a small number of Indian villages, find that parents favor equal treatment of children, but also find evidence of pro-male bias in intrahousehold allocation of resources during the lean season, when resource constraints are more likely to bind. Jensen (2002), building on insights from Yamaguchi (1989), discusses how gender bias in average outcomes may arise even if females are not discriminated against in the intrahousehold allocation of resources, but if girls are more likely than boys to live in families with more siblings, and hence less resources per head. Such differences in the number of siblings may emerge if preference for sons induces families to have more children whey they have not yet achieved the desired number of sons.

The fact that resource constraints - coupled with pro-male bias in economic opportunitiesappear to provide an economic "rationale" for the existence of gender bias, might lead one to expect a path towards equalization as a consequence of economic development, if this is accompanied by an increase in the resources available to households. However, it has been observed that female discrimination in India is not limited to the poorest and least educated households. In fact, in some studies it actually appears to be more frequent among certain high castes (Das Gupta (1987)). Similarly, it has been suggested that the decline in fertility that has accompanied economic development in India may have contributed to a worsening of gender bias, as the desired number of sons may have decreased less quickly than the desired total number of children (Das Gupta and Bhat (1995), Basu (1999)). Anderson (2003) constructs a model where economic development, in a caste-based society, leads to an increase in dowries. This might lead to an increase in son preference. Goldin (1995), among others, documents the existence of a U-shaped female labor force participation rate as a function of economic development, so that the role of women as bread earners might decrease in the first stages of development. Overall, these observations lead to ambiguous predictions on the relation between son preference and economic development.

Child weight and height performance can be viewed as the output of a health production function whose inputs include elements such as nutritional intakes, exposure to infections, and health care (as well as, of course, genetic predisposition). In this sense, height and weight are affected by virtually all of the pathways through which gender bias operates. When evaluating gender differences, another advantage of nutritional status versus, say, nutrient intakes, morbidity, or health care, is that the former is relatively easily measured, and therefore much less prone to measurement error or reporting bias.

To evaluate changes in nutritional status, we transform the anthropometric indicators into $z$ -

\footnotetext{
${ }^{2}$ There are clear exceptions, such as the importance of males in performing certain religious rituals, which is especially common in North India.
} 
scores, that is, we normalize the indicators by using mean and standard deviation of the same index for children of the same gender in a reference population. The use of z-scores is common in nutritional studies (more on this below), and two reasons make its use particularly useful for our purposes. First, it facilitates comparisons between genders, as nutritional status is evaluated relative to children of the same gender in a reference population where boys and girls are, on average, equally well nourished. Second, it allows to pool together children of any age, so that one can simply evaluate the overall nutritional status in a population estimating nonparametrically the whole distribution of the z-scores. Indeed, this second advantage of using z-scores is crucial for our purposes, as most of our results are based on the comparison of cumulative distribution functions of z-scores between genders (for a given wave) or over time (for a given gender).

Overall, we find that in urban areas child nutritional status in India improved substantially during the 1990s. In rural India, which account for the bulk of the total population, our results show large improvements in short term measures of nutritional status, while height-for-age (a measure of long term nutritional status) improved much less. We also find that gender inequality in nutritional status increased, with nutritional status improving substantially more for boys than for girls. We also document the existence of apparent geographical differences in these changes: the gender differences in the changes in nutritional status are particularly striking in rural areas of North and East India, areas where the existence of widespread son preference has been documented by an immense body of research.

In the second part of the paper we explore alternative explanations for the observed trends. First, we consider (and exclude) the possibility that rural to urban migration and changes in infant mortality are driving the differences in the changes between sectors and genders. Second, we study the relation between changes in child nutritional status and changes over time in a list of economic and demographic variables defined at the child, household, and community level that should be strongly associated with child growth performance. Overall, we find that changes over time in the level of the predictors explain a sizeable fraction of the overall change in the distribution of height-for-age z-scores, while the improvements in weight-for-height remain largely unexplained. Oaxaca decompositions of the probability of stunting and wasting confirm that for both genders, and across all of India, most of the change in anthropometric performances is explained by changes in the regression coefficients that related the z-scores to the predictors, rather than by changes in the predictors themselves. However, a detailed analysis of the patterns of the changes in the coefficients does not point to a simple explanations for the emerging gender differences we document.

The paper proceeds as follows. In the next section we describe the dataset. In Section 3 we discuss the anthropometric indicators which represent the main outcome of interest of our analysis. In Section 4 we document the extent of gender differences in child nutritional status, and we study how the distribution of anthropometric indices changed between the two NFHS waves. In Section 5 we provide a first attempt at explaining the observed changes. Section 6 concludes. 


\section{Data}

The primary source of our data is the two waves of the Indian National Family and Health Survey (NFHS) available at the time of writing. The NFHS is one of the many Demographic and Health Surveys that have been carried out in several developing countries with the primary purpose of collecting information on health, fertility and other family issues from ever married women of fertility age. The first wave (NFHS-I) was completed between April 1992 and August 1993 with a sample of ever married women of age between 13 and 49. The second wave (NFHS-II) was completed between November 1998 and December 1999, sampling ever married women of age 15-49. ${ }^{3}$ Each survey contains reports from approximately 90,000 women, sampled from all Indian states using a stratified and clustered survey design. In all our calculations we make use of the sampling weights contained in the survey, and we report separate results for urban and rural areas.

The largest component of the surveys is an individual questionnaire administered to each ever married woman of fertility age in the sample. The questionnaire also includes information on health, contraception and fertility preferences, as well as a complete birth history and very detailed information on the health status of younger children. ${ }^{4}$ In particular, height and weight were measured for children below age 4 in NFHS-I, and below age 3 in NFHS-II. Because of lack of appropriate measuring tools, height was not measured during fieldwork in the first states covered by NFHS-I. These states, which formed the so-called Phase I of the survey, are Andhra Pradesh, West Bengal, Himachal Pradesh, Madhya Pradesh, and Tamil Nadu. To enhance comparability, we will then base most of our results on states and age groups that are represented in both waves. We will refer to the states for which height was recorded in 1992-93 as Phase II states. A separate questionnaire administered at the household level contains several household characteristics, including a complete household roster, and individual information on work status, educational attainment, and a few selected health indicators. Finally, in rural areas a village questionnaire records information on village characteristics

Tables 1 and 2 report selected summary statistics at the household and individual level. For several statistics we also present a geographical breakdown following the geo-cultural classification proposed by Sopher (1980) and utilized, amongst others, by Bourne and Walker (1991), Dasgupta (1993) and Dyson and Moore (1983). The major Indian states are then grouped into three regions as follows: North includes Delhi, Gujarat, Haryana, Himachal Pradesh, Jammu, Madhya Pradesh, Punjab, Rajasthan and Uttar Pradesh. Assam, Bihar, Orissa and West Bengal form the Eastern region, while the South includes Andhra Pradesh, Karnataka, Kerala, Maharashtra and Tamil

\footnotetext{
${ }^{3}$ We ignore the difference in the lower bound of mothers' age in the waves, as less than $0.5 \%$ of women in NFHS-I were 13 or 14 years old.

${ }^{4}$ NFHS-II also contains questions related to quality of available health care, the woman's empowerment within the household, AIDS awareness, mother's anthropometric indicators, and mother and children's anemia. We do not use such information as it is not available in the first wave. Also, some observers have raised doubts on the reliability of some of these variables (see Irudaya Rayan and James (2004)).
} 
Nadu. All results reported by region in the paper only include the major Indian states listed above, while they exclude Union Territories (which account for less than 5 percent of the population).

Many indicators suggest that important changes are taking place. The figures in Table 1 show a fertility decline, both in cities and in rural areas. Average household size declined by about 0.2 persons, and the number of children below age 5 by about $0.1 .^{5}$ We also observe a decline in desired family size, which is defined as the ideal number of children that a respondent with no children would like to have, or the ideal number she would have liked to have if she could go back to the time she did not have any. The use of contraceptives increases between the two surveys. In urban areas, the proportion of women who do not practice any form of birth control declined from 52 to 45 percent. In rural areas the proportion declined from 65 to 58 percent.

The figures reported in Table 2 refer to variables that have often been used as indicators of gender inequality. These include direct measures of preference for sons, male versus female schooling achievement, and the role of women as bread earners. The desired proportion of girls, calculated from numerical answers to direct questions about the "ideal" number or sons and daughters, displays the expected North-South gradient, with much stronger son preference in the North, especially in rural areas. Interestingly, in every region and sector, the mean proportion of children that are desired to be girls is higher in 98-99 than in 92-93, even if all the figures remain below one half. In the North, the proportion of desired girls increases by approximately one percentage points in both rural areas (where it was $38 \%$ in NFHS-I) and in towns (where it was $41.9 \%$ ). In the South the proportion increases from 46.3 to 47.2 percent in cities, and from 43.5 to 45.6 percent in rural areas. Similar patterns emerge in Eastern states. ${ }^{6}$

Looking at female labor force participation, three patterns are apparent. First, in every region, and in both waves, women are much more likely to work in rural than in urban areas, where participation rates are about $40 \%$ lower than in the countryside. Second, participation rates have increased over time in all areas, especially in the North, where participation rates increased from 16.2 to 21.2 percent in urban areas, and from 29.5 to 37.3 in rural areas. Third, participation rates are about twice as large in the South than in the North, both in cities and in villages. For example, in NFHS-II 61.2 percent of women worked in the rural South, while only 37.3 percent did in rural North. In Eastern states women participation is even lower than in the North. The proportion of working women who are also earning money shows instead a very stable picture. In urban areas the fraction remains close to 90 percent in all regions. While in rural South approximately three quarters of working women also receive earnings, the proportion is only two thirds as large in the North.

\footnotetext{
${ }^{5}$ However, some observers, citing evidence from other data sources, have suggested that NFHS-II may have underreported the number of births (see Irudaya Rayan and James (2004), and references therein).

${ }^{6}$ If we interpret non-numerical responses - which may include answers such as "up to God" — as expressing indifference with respect to child gender, the results are qualitatively identical, with only a generalized small decrease in son preference, which arises by construction.
} 
Female illiteracy rates once again confirm the familiar North-South pattern. In 1992-93, almost 80 percent of ever married women of fertility age that live in Northern states had no formal education. In the South the proportion was still very high, but 20 percentage points lower. The gradient is also clearly present in urban areas, but at levels approximately 50 percent lower. Illiteracy is significantly less common among sample women's partners. Note also that there is no clear North-South gradient in illiteracy for men, so that one cannot easily interpret the gradient in women's illiteracy as indicating geographical differences in availability of (or general attitudes towards) schooling. All these patterns are still present in 1998-99, but there are clear signs of improvements over time, as formal education is becoming more common both for men and for women. The last rows of Table 2 show a remarkable increase in the proportion of both men and women with at least a secondary degree. In urban areas of all regions the percentages for women are approximately three times as large in NFHS-II as in NFHS-I. Overall, the proportion increases from 10.7 to 32.8. The figures are much lower in rural areas, but in relative terms the increase is even larger, as the overall proportion of women with at least a secondary degree increases from 0.8 to 7.7 percent. These statistics are clearly very rough measures of the socio-economic role of women in India, but overall they seem to point to an improvement in women's standing relative to men during the 1990s.

In the next section we turn to the description of the anthropometric indicators of child nutrition that form the core of our analysis. The first rows of Table 2 show that the number of children of age 0-3 in both NFHS-I and NFHS-II is quite large, even when we disaggregate at the sector and region level, ranging from 963 in Urban East in 1992-93, to 10,870 in rural North in 1998-99.

\section{Child Nutritional Status: Measurement}

The use of anthropometric indices to evaluate child nutritional status is a well-established practice (see, for instance, Waterlow et al. (1977), WHO Working Group (1986), Gorstein et al. (1994)). Height (given age) is the preferred measure of long-term nutritional status, as it reflects both current and past nutritional status. Because weight can change in a relatively short period of time as a consequence of changes in nutritional intake and/or health status, weight-for-height is a better measures of short term nutritional status. Weight-for-age can also change rapidly, but-unlike weight given height - does not distinguish between small but well fed children and tall but thin ones, and so can be seen as a combination of the other two indices. For this reason, in most of our empirical results we will omit weight-for-age from the analysis. Note finally that weight-for-height has the advantage over both the other indices of not depending on the availability of correct reports on child age in months. ${ }^{7}$

\footnotetext{
${ }^{7}$ Age is very frequently misreported in household surveys, especially among respondents with low levels of literacy. Our analysis of the empirical distribution of reported age in months within the NFHS suggests that age misreporting
} 
Let $x_{i g}$ represent weight or height of a specific child $i$ in a "group" $g$. When the indicator measures height, the group is defined by age and gender. When the indicator measures weight, the reference group is identified by gender and either age (in the case of weight-for-age) or height (in the case of weight-for-height). To gauge the nutritional status of a child, it is necessary to compare the child's outcome to a corresponding 'normal' outcome for a child that belongs to the same group. The common practice is to make use of $z$-scores, calculated as $\left(x_{i g}-x_{g}\right) / \sigma_{g}$, where $x_{g}$ and $\sigma_{g}$ are respectively the mean (or median) and the standard deviation of the indicator for children within the same group in a reference population. Z-scores are then easy to interpret if the corresponding nutritional indicator is approximately normally distributed in the reference population. If, say, a boy has a weight-for-height z-score below -1.645 then his weight is below that of 95 percent of boys in the reference population with the same height. ${ }^{8}$ Children are said to be stunted if their height-for-age z-score is below -2 , and wasted if their weight-for-height is below the same threshold.

Both NFHS waves report z-scores calculated adopting the 1977 CDC growth charts for American children as a reference. These reference growth charts have been widely used as an international standard for cross-country anthropometric comparisons and their use as a reference has been recommended by the World Health Organization (Dibley et al. 1987a, 1987b). Such recommendations are based on evidence supporting the hypothesis that well-nourished children in different population groups follow very similar growth patterns (Martorell and Habicht (1986)). Agarval et al. (1991) and Bhandari et al. (2002), show that these charts describe reasonably well the growth process of Indian children living in affluent families. ${ }^{9}$

Although changes over time of mean nutritional status can be evaluated without the use of reference growth charts, we choose to make use of z-scores because we are also interested in boy versus girl nutritional status. The use of z-scores facilitates such comparisons, as boys and girls have different growing patterns. Moreover, the use of z-scores is convenient because it allows one to construct a measure of nutritional status comparable across all age groups, and whose distribution can be easily tracked over time.

\section{Child Nutritional Status in the 1990s}

In Figure 1, we plot nonparametric locally weighted regressions (Fan (1992)) of z-scores on age, pooling all observations from NFHS-I. All the patterns of the z-scores are consistent with what is

is not a serious issue for this dataset. In particular, there is no evidence of peaks at focal ages such as 6 months, one year etc..

${ }^{8}$ In reality, anthropometric indicators are not exactly described by normal distributions. Recently revised pediatric growth charts for American children account for this, and provide an alternative method for the calculation of z-scores that still retains their interpretation in terms of quantiles of a normal distribution. For details, see Kuczmarski et al. (2000).

${ }^{9}$ However, see Klasen (1999) and Klasen and Moradi (2000) for a more skeptical view on the appropriateness of the CDC references. 
commonly observed in low-income countries (see, e.g., Shrimpton et al. (2001)), and show weight and height performances which are, on average, well below those of the American children in the reference population. The curve for weight-for-age starts below zero, declines until the age of about eighteen months, and then stabilizes below -2 . The mean weight performance is therefore approximately equal to that of the first percentile of the reference population. Height-for-age, which represents a measure of long-term nutritional status, presents an even more striking pattern, and the regression is still sloping downwards (and approximately equal to -3) for 4-year old children. Because most low-weight children are also small, the weight-for-height indices show a degree of wasting much lower than that of stunting, and the z-scores curve remains close to -1 . Note also that the degree of wasting decreases for older children.

In order to analyze changes over time in child nutritional status, we study the changes in the whole distribution of z-scores for a given geographical area and demographic group. First, we estimate the densities nonparametrically using a biweight kernel, and choosing the bandwidth using the robust criterion proposed by Silverman (1986). Then, we calculate the cdfs by numerically integrating the densities. ${ }^{10}$ Finally, for a given value $z$ of the z-scores, and letting $F$ denote the cumulative distribution function, we calculate the differences in the distributions as $F_{98-99}(z)-$ $F_{92-93}(z)$, so that improvements will be reflected by negative numbers. Other researchers have used analogous differences to evaluate changes over time or discrepancies across countries in the distribution of indicators of nutritional status (see e.g. Sahn and Stifel (2002), Strauss et al. (2004)).

Figure 2 plots the results for weight given height, by sector, for all children less than 36 months old in all Indian states where height was recorded in NFHS-I. Both in rural and urban areas the distributions of z-scores shift markedly to the right, indicating large improvements. In the top rows of Table 3 we report the results of a battery of tests of comparisons between distributions of weightfor-height z-scores. The figures in columns 1 and 4 are p-values of Kolmogorov-Smirnov tests of equality between the two distributions, so that the null that is being tested is $H_{0}: F_{98-99}(z)=$ $F_{92-93}(z) \forall z$. The p-values are calculated using simulations, using the bootstrap procedure described in Abadie (2002). The test statistic is based on the supremum of the absolute value of the differences $F_{98-99}(z)-F_{92-93}(z)$ calculated over a grid of points over the support of $z$ (the difference is rescaled by a factor that is a function of sample size in the two distributions). We use a 50-point grid over the interval $\left[\begin{array}{ll}-3 & 1\end{array}\right]$, and for each test we use 250 replications, adopting block bootstrap to take into account the clustered survey design. In columns 2 and 5 we calculate analogous simulationbased tests for the null $H_{0}: F_{98-99}(z) \leq F_{92-93}(z) \forall z$, that is, we test the null hypothesis that the distribution of z-scores in 1998-99 (weakly) first order stochastically dominates the distribution in 1992-93. This test statistic is based on the rescaled supremum of the differences described above. In both rural and urban areas, the null of equality is clearly rejected at standard significance levels, while there is strong support for the null of first order stochastic dominance. Columns 3 and 6

\footnotetext{
${ }^{10}$ We prefer this estimation strategy to the alternative of estimating CDFs directly, as the direct estimation of CDFs leads to lines that are excessively jagged.
} 
report the results of an intersection-union test of no stochastic dominance, that is, the null is $H_{0}: F_{98-99}(z)>F_{92-93}(z)$ for some $z \leq \bar{z}$ (Howes (1996), Davidson and Duclos (2000)). The null is rejected in favor of the alternative that the distribution in 1998-99 first order stochastically dominates the distribution in 1992-93 (or vice-versa) if all differences $F_{98-99}(z)-F_{92-93}(z)$ calculated over a grid of points are negative (positive) and all pointwise tests of equality reject the null. For each anthropometric index we display the range over which the null is rejected using a 10, 5 or 1 percent significance level. We use the same grid as for the KS tests, and we calculate all pointwise tests taking into account the presence of intracluster correlation. ${ }^{11}$ In urban areas, and using either a ten or a five percent significance level, the null of no stochastic dominance is rejected over the whole grid in favor of the alternative that the more recent distribution first order stochastically dominates the earlier one. In rural areas the null is rejected over the whole range using a 10 percent level, and until -.877 using a 5 percent level. The null is not rejected in either sector if we use a one percent significance level.

The change in the distribution is not only statistically significant, but also very large in practical terms. For instance, in rural areas the proportion of children who are wasted (that is, whose weightfor-age $\mathrm{z}$-score is below -2) decreased by about 3 percentage points, while the decrease is larger than 5 percentage points in urban areas. These are large changes, especially once we take into account that the two surveys are separated by only six years. The changes become even more impressive once we transform these percentages into actual headcounts. According to NFHS-II, the urban sector of Phase II states (for which height in the previous round was recorded) accounted for 18.2 percent of the total Indian population, and the rural sector accounted for approximately half. In the same states, children below age 3 represented approximately 6 percent of the total population in urban areas, and 7.5 percent in the countryside. With the total Indian population reaching one billion at the end of the 1990s, the estimated changes in cdfs in urban areas indicate that in 1998-99 there are approximately 550,000 fewer stunted children than those that there would have been if the cdf remained the same as in $1992-93\left(10^{9} \times 0.06 \times 0.182 \times 0.05\right)$. In rural areas, the reduction in the number of wasted children amounts to about 1.1 million $\left(10^{9} \times 0.075 \times 0.51 \times 0.03\right)$.

The results for height-for-age (Figure 3) are mixed. In urban areas child height is improving significantly: the proportion of children with z-score below -2 or -3 decreases by approximately three percentage points, and the distribution for 1998-99 remains below that for 1992-93 for all negative values of $z$. The p-value of the KS test of equality (column 4 in the central rows in Table 3 ) is 0.06 , and the null of weak first order stochastic dominance (column 5) is strongly supported. The intersection-union test (columns 6) rejects the null of no dominance over the range -4 to -1.55 . However, in rural areas our results indicate a striking lack of improvement. The difference between the cdfs indicates that there is virtually no change over time in height performances, as confirmed

\footnotetext{
${ }^{11}$ Note that this test being an intersection-union test, it is quite conservative, so that the actual size will be generally lower than the nominal size. Note also that this test never rejects the null if the chosen grid includes points too far along the tails of the distributions, as all cdfs are identical (either one or zero) at extreme points.
} 
also by the tests in Table 3. Hence, while in both sectors measures of short term nutritional status indicate large improvements, in rural areas the level of chronic malnutrition appear to have remained overall remarkably stable.

The results described so far exclude Phase I states, that is, Andhra Pradesh, Himachal Pradesh, Madhya Pradesh, Tamil Nadu and West Bengal. Overall, these five states account for approximately 25 percent of the total Indian population. In Figure 4 we compare the changes in distributions for states with non-missing height with those estimated with the inclusion of Phase I states for the only anthropometric indicator for which such comparison is possible, that is, weight given age. Overall, the two estimated changes are very close in urban areas. In rural areas the inclusion of Phase I states lead to larger improvements, so that our conjecture is that in restricting our attention to states for which height was recorded in both rounds we are underestimating the overall improvements in child nutritional status. ${ }^{12}$ For brevity, in the rest of the paper we will abandon weight-for-age as a measure of nutritional status, as this indicator is just a combination of height-for-age and weight-for-height.

\subsection{Towards More Gender Inequality?}

The results described so far show large improvements in short-term measures of child nutritional status across all of India, as well as sizeable improvements in long-term performances in urban areas. In this section we show that these changes hide large gender differences, especially in rural India. Figure 5 describe sex-specific changes over time in the distribution of weight-for-height and heightfor-age. The differences are calculated as before as $F_{98-99}(z)-F_{92-93}(z)$, so that improvements are represented by negative values. In rural areas, stark gender differences emerge: the change in the distribution of weight-for-height z-scores is about twice as large for boys as for girls, and while boys' height performances show a relatively small improvement (the cdf evaluated at -2 drops by approximately 0.02), for girls we observe an almost specular worsening. These differences are confirmed by the test results reported in Table 4. The changes in height are small enough that for both genders the KS test of equality does not reject the null of no change at conventional levels (column 1). The test of stochastic dominance is not rejected either (column 2), but because the null is of weak stochastic dominance, this result is a simple confirmation of the small changes. The intersection-union tests never reject the null of no first order stochastic dominance. The tests for boys' weight-for-height strongly support the null of first order stochastic dominance. The KS test for girls gives the same result, while the null of no dominance is not rejected by the intersectionunion test, which is more conservative. The bottom two graphs in Figure 5 show that changes appear to be much more similar between genders in urban areas. Improvements in boy weight-forheight are large and similar to those observed in rural areas, but girls appear to be doing much

\footnotetext{
${ }^{12}$ This conjecture is also supported by the observation that the distribution of height-for-age in 1998-99 (not reported here) improves when all states are included. The results are available upon request.
} 
better as well: for instance, the proportion with z-score below -2 decreased by approximately six percentage points between 1992-93 and 1998-99 for both boys and girls. However, there still is a gender gap in the change for z-scores between -2 and -1 . This is confirmed by the intersectionunion tests, which reject the null of no dominance over a larger range (and for smaller significance values) for boys than for girls. Changes in height-for-age are more unequal, as reflected also in test results reported in Table 4: while the cumulative distribution function decreases for girls by about 2 points for $z$ in the interval between -4 and -2 , the drop for boys is approximately twice as large.

The changes over time are clearly silent about the gender differences in the cdfs in each NFHS round. Because z-scores are normalized using gender-specific growth charts, similar nutritional status for boys and girls relative to the reference growth charts should translate into differences in cdfs close to zero. In Figure 6 we plot period-specific differences $F_{\text {boys }}(z)-F_{\text {girls }}(z)$, so that we read negative gaps as "boy advantage". In 1992-93 (continuous lines) there is no clear evidence of generalized female disadvantage in nutritional status, as evaluated relative to US growth charts. ${ }^{13}$ In fact, in both sectors and for almost all values of $z$, growth performances appear to be relatively better for girls. For example, in rural areas the proportion of girls whose weight-for-height z-score is below -2 is about 3.5 percentage points lower than for boys. In urban areas differences are generally very small, especially for height-for-age. The curves calculated from NFHS-II (dashed lines), show instead a clear and striking change, especially in rural areas, where in 1998-99 all curves lie virtually everywhere below the corresponding curves in the previous NFHS wave, indicating a clear movement towards male relative advantage in nutritional status. In NFHS-II, the proportion of girls whose weight-for-age z-score is below -2 becomes approximately identical to that for boys. The difference in the proportion of stunted children preserves the same magnitude as in NFHS-I but the sign is reversed. In urban areas we observe a small change towards boy advantage over part of the range for weight-for-height, and a clear movement towards negative values over much of the range for height.

To analyze whether the change in the gender difference in distributions is not only large in magnitude but also statistically significant, in Figure 7 we plot sector-specific "differences-in-differences" of cdfs' for all India, calculated as

$$
\left[F_{\text {boys }}^{I I}(z)-F_{\text {girls }}^{I I}(z)\right]-\left[F_{\text {boys }}^{I}(z)-F_{\text {girls }}^{I}(z)\right]
$$

where the superscripts denotes the NFHS wave. Because "relative boy advantage" translates into negative values of each difference, an increase in boy advantage will be represented by a negative difference-in-differences. We construct 95\% confidence bands using bootstrap, with 250 replications. In each replication, and independently for rural and urban areas, we first resample clusters separately from each NFHS round. We then re-estimate all the difference-in-differences at each replication and calculate the value of the lower and upper bands for each point on a grid as the 2.5

\footnotetext{
${ }^{13}$ Borooah (2005) finds analogous result with respect to height-for-age, using data collected from the rural areas of the larger Indian states in 1993-94 by the National Council of Applied Economic Research.
} 
and 97.5 percentiles from the bootstrap distribution. Because resampling with clusters includes all observations for a selected cluster, this procedure takes into account both intracluster and intrahousehold correlation, so that the confidence intervals should have correct coverage rates. The confidence bands in Figure 7 show that in rural areas, and especially for weight-for-height, the increase in boy advantage is large, and for most of the relevant range the upper band lies below zero, indicating that over this range the null hypothesis of no change in the gender gap would be rejected at the $5 \%$ significance level. In urban areas the difference-in-differences below zero are also negative, but in this case the bands include zero throughout the whole range.

\subsection{Geographical Differences}

In this section we study the possible existence of geographical patterns in the gender-specific changes in nutritional status. Even if the geographical pattern in the extent of gender inequality is related to social and cultural factors, we do not necessarily expect these factors to affect child outcomes in a time-invariant way. Some of these factors may themselves change, for instance because of increased female schooling or labor force participation, but (as we have described in the introduction) the way these factors affect child outcomes may also change as a consequence of shifts in economic constraints. Indeed, past research has documented how the extent of gender inequality (as expressed for instance in the female-male ratio) has been changing differently in different Indian states (see, e.g., Drèze and Sen (1995), Drèze and Sen (2002)). Ideally, it would be interesting to conduct a separate analysis for each state. However, in order to preserve a relatively large number of observations in each area, we separate India into three broadly defined regions-North, East, and South-following the geo-cultural classification proposed by Sopher (1980). As in the previous section, for comparability reasons we only include children up to 3 years old, and we exclude from the analysis the states for which height is missing in NFHS-I. The remaining states are then grouped as follows: North combines Gujarat, Haryana, Jammu, Punjab, Rajasthan, Uttar Pradesh, and New Delhi; East is composed of Assam, Bihar, and Orissa, while Kerala, Karnataka and Maharashtra represent the South. Table 5 reports the proportion of stunted and wasted children for each sector, gender, and NFHS round, together with the corresponding standard errors and the number of observations used in the calculations. Figures 8 to 10 display the differences-in-differences estimated as described in section 4.1. ${ }^{14}$ Several striking differences are apparent, both across different regions and between rural and urban areas within the same region.

The results for North India (rows B and F in Table 5) are relatively similar to those for the whole country. This is perhaps not surprising, as North India accounts for approximately half of all observations (see Table 2). In 1992-93 approximately half of children of age 0-3 living in rural areas are stunted, while the proportion is about five percentage points lower in urban areas. The

\footnotetext{
${ }^{14}$ For reasons of space we omit the graphs for the changes over time in the distributions and for the gender differences in distributions, as well as the tests of stochastic dominance. These additional results are available upon request.
} 
extent of wasting is much lower, and affect less than 20 percent of children in each sector. Notice that, overall, nutritional status of girls appears to be better than for boys, at least relative to the growth charts we use as reference. However, in 1998-99 we observe an overturn of this relation, with the exception of weight-for-height in urban areas. The prevalence of stunting in urban areas remains virtually unchanged for girls while it decreases from 45.1 to 39.3 percent for boys. In rural areas there is instead an increase in stunting, and the increase for girls (from 50.5 to 55.4) is more than twice as large as that for boys (from 50 to 51.9). Looking at wasting (row F), we find instead very large improvements in both sectors, but especially in urban areas, where the proportion below -2 drops by 50 percent for girls (from 16.4 to 8.2) and decreases from 18.1 to 10.6 percent for boys. However, in rural areas the drop is clearly larger for boys. When we examine changes in the gender differences of the whole distributions (Figure 8), we find a clear movement towards male advantage in the rural sector for both stunting and wasting (even though it is not statistically significant over most of the range). In urban areas the graphs remain below zero for almost all negative z-scores, but the differences are estimated imprecisely, so that the confidence bands always include zero.

In the Eastern region (rows $\mathrm{C}$ and $\mathrm{G}$ in Table 5), we observe large improvements in height for both genders in urban areas, and only for boys in the rural sector, where the extent of stunting slightly increases among girls. In both NFHS rounds, the extent of stunting is of similar magnitude as for Northern states. In urban areas, the proportion of boys who are wasted is slightly higher in 1998-99 (20.7 percent) than in 1992-93 (19.5), but the proportion of girls increases considerably from 11.8 to 15.9. In the rural sector we find instead an increase in wasting among girls (from 18.7 to 20.9) and a sizeable decrease for boys (from 25.7 to 21.6). Looking at the changes in the whole distributions, the differences-in-differences in Figure 9 show stable gender differences in stunting in urban areas, and an important movement towards male advantage in all other cases, where zero remains outside the $95 \%$ confidence bands over large sections of the range of z-scores.

The picture for the South, which here includes Kerala, Karnataka and Maharashtra, is completely different. First, note that while the extent of wasting is roughly comparable to that of other regions, the extent of chronic malnutrition is clearly much lower, so that the proportion of stunted children of either sex is always approximately 30 percent smaller than in North or East. Note also that the degree of stunting remains relatively stable over time. The level of wasting shows instead large improvements in urban areas (where is drops from 19.7 to 14.8 percent for girls, and from 19.5 to 16.3 percent for boys) and little change in the countryside. The picture emerging from the differences-in-differences (Figure 10) is very different from that in the other region, and in no case do we see a clear movement towards male advantage. The curves always remain close to zero, and over large ranges we even observe positive figures, which indicate relative gains for girls. However, zero never lies outside the $95 \%$ pointwise confidence bands, so that the null of no change in gender differences in the distributions cannot be rejected.

Overall, we observe important movements in the distribution of weight and height for age z- 
scores during the short period of time between the two waves of the NFHS, but we also find that in rural areas of Northern and Eastern states boys appear to have benefitted much more than girls from a period of rapid economic growth. Only in Southern regions, and in urban areas elsewhere, do we find clear improvements in the nutritional status of children (up to 3 years old) for both boys and girls. It is somehow disturbing that areas where son preference has historically been found to be stronger - and in a period of rapid growth - appear to be moving towards a situation of more pronounced gender inequality in child nutritional status.

\section{Explaining the changes}

In the previous pages we have shown that the gender differences in the changes in the distribution of z-scores have been markedly different between sectors and across different geographical regions. In this section we analyze several potential explanations for these trends. First, we consider the role that rural to urban migration may have had in shaping the differences between the two different sectors. Then we consider the possible role of changes in boy versus girl mortality in shifting the gender-specific distributions. Finally, we study the relation between changes in child nutritional status and changes over time in a list of economic and demographic variables - defined at the child, household, and community level - that should be strongly associated with child growth performance.

\subsection{Migration}

In principle, the observed changes could be at least partly explained by migration across different areas, rather then by real changes in the nutritional status of children in the relevant age group. For instance, the decline over time of girls' height performances in rural areas and the simultaneous improvement in urban areas (see Figure 5) could be explained at least in part by selective migration of better off families from rural to urban areas. A similar argument could justify the difference in the improvements in height indicators for boys between rural areas (where small changes are observed) and urban areas (where improvements are more marked).

In this section, we argue that migratory patterns are unlikely to be an important driving force of the observed changes in growth performances. The overall extent of migration in India has been relatively low during recent years, as documented, for instance, in Topalova (2005) and Munshi and Rosenzweig (2005). Topalova (2005), using data from the Indian National Sample Survey, shows that in 1999-2000 3.6 percent of the rural population reported changing either district or sector during the previous 10 years. The proportion is instead higher (13.1 percent) for urban respondents, but economic considerations are cited as a reason for moving by less than a third of them. Munshi

and Rosenzweig (2005) with data from the Rural Economic Development Survey (a representative sample of rural Indian households) estimate that the proportion of men who migrated out of their village of origin was low and actually declined between 1982 and 1999. 
However, none of these figures is necessarily very informative about the migration patterns of families with children of age 0-3. Because most children are born from relatively young parents, who are more likely to migrate, migration rates may be much larger than for the overall population among families where the children in our sample were born. According to the limited information on migration included in the NFHS, in urban areas 52 percent of the children of age 0-3 in 1998-99 were born from mothers who moved to their current residence during the six years before the survey, while the corresponding figure for rural areas was 41 percent (Table 7). However, the figures are much lower when we look at the proportion who moved and changed sector. The fractions become 25 percent in urban areas and only 5 percent in rural areas, where the vast majority of moves are likely to be associated with marriage exogamy. Because the NFHS does not include any information on the state of previous residence, we cannot estimate the fraction of children born from mothers who moved from a different state. Note also that there is virtually no difference between the proportion of boys and girls born from mothers who recently changed residence, suggesting that the gender differences in the changes in growth performance are unlikely to be associated with selective migration of parents.

If richer families (who are able to raise taller and better nourished children) moved disproportionately to urban areas, and if no real overall improvement in nutritional status took place, we would expect the distributions of z-scores in rural areas to show a decline in nutritional status. However, we only observe a decline in growth performances for girl height-for-age, and not for other indicators. Also, such form of selective migration would lead us to expect the improvement in the distributions of z-scores for urban children whose mothers did not move between waves to be smaller than the overall change for the urban sector (because in this scenario, the overall change would also include the inflow of well-fed children). In Figure 11 we compare the overall changes over time in the urban gender-specific distribution of z-scores (plotted as continuous lines) with those estimated

including only children born from mothers who did not migrate from the rural sector between the two NFHS rounds. There is no evidence that non-migrants have improved less. If anything, rural to urban migration somewhat reduces the overall gain for the urban sectors (especially for girls) suggesting that families that move from rural to urban areas are actually poorer than others who have been living in cities for a long period of time.

\subsection{Changes in Mortality}

In this section we explore the possibility that changes in child mortality may be partly responsible for the gender differences in changes in growth performance that we have documented in Section 4. Our analysis suggests that this possibility is not plausible.

Several studies have documented the existence of a male advantage in the survival probability of young children, a phenomenon especially pronounced in North India. At the same time, we have shown that, in 1992-93, in rural areas of North and East India, girls appeared to have z-scores no 
worse (or even better) than boys. In principle one could reconcile these two results hypothesizing that, in very poor households, resources allocated to girls are not sufficient to guarantee their survival if their nutritional status is below a certain threshold, while son preference is such that boys are taken care of to the extent that they are likely to survive even with very low z-scores. Then, the impact of poverty reduction on the distribution of z-scores for girls may have been reduced if the more recent distribution includes girls with very low z-scores that would not have survived in the earlier period. For this argument to be a leading cause of the observed gender differences in changes in nutritional status, we should expect large improvements in girl survival rates, and larger improvements for girls than for boys.

Because the NFHS includes a complete birth history, we can estimate survival probabilities for both rounds. For each round, we calculate survival probabilities to age three including only data from the five years before the survey. This minimizes the likelihood of recall errors, and ensures that all births used in the calculations for 1998-99 took place after the conclusion of NFHS-I. We calculate the probability of surviving up to age three as $1-\prod_{i=0}^{3}\left(1-q_{i}\right)$, where $q_{0}$ is neonatal mortality (within the first month of life), and $q_{i}$ is mortality between $(i-1)$ and $i$ years of age. For each sector and NFHS round, we estimate separate mortality rates for boys and girls, for all India as well as for each separate geographical region. We also estimate gender differences in mortality rates, and we finally estimate both gender-specific changes over time in mortality rates and the changes over time of the gender differences. Because all statistics are non-linear combinations of estimated parameters (the $q_{i} \mathrm{~s}$ ), we estimate standard errors using 250 bootstrap replications, taking into account the complex survey design. All results are included in Table 8.

Mortality rates are clearly very high. In 1992-93, the figures for all India indicate that in urban areas, for every 1000 births of a given gender, 67 boys and 71 girls did not survive to the age of 3, while in rural areas the figures were 107 and 114 respectively. To put these figures into perspective, the World Health Organization estimated that, in 1992, only 10 children out of one thousand born in the United States did not survive to the age of five (World Health Organization (1995), Table 6). The figure for all India show, as expected, higher mortality rates for girls than for boys (see panel C) but such differences are small and not statistically significant at standard confidence levels. However, geographic disaggregation show that male advantage is larger in North and East, while the sign of the differences is reverted in the South. In particular, looking at differences that are statistically significantly different from zero, girls have a two percent higher probability of dying before age 3 in rural areas in the North, and a 1.5 percent lower probability of not surviving in rural South. Moving to 1998-99, we can see that mortality rates show generalized declines, with the exception of the results for girls in the North and in rural South, and for boys in rural North. However, the few estimated increases in mortality are very small and not statistically significant. Improvements in mortality rates appear particularly discouraging in North India, where no significant change is observed. Eastern states experienced the largest improvements (especially 
for girls), with reduction in mortality ranging from -1.4 percent (for boys in urban areas) to -4 percent (for girls in the same areas). In the South mortality rates decreased by slightly more than 1 percentage point in both sectors for boys and in urban areas for girls. Looking at the figures in columns 5 and 6 of panel $\mathrm{C}$, these results do not lend much support to the hypothesis that changes in mortality rates play an important role in explaining the observed gender differences in changes in nutritional status observed in North and East India (especially in rural areas). In fact, in Northern states (which account for about half of the children in the sample) there is virtually no change in the probability of survival up to age 3. In Eastern states survival probabilities do increase more for girls than for boys, but the difference is too small to explain the large difference-in-differences in cdfs observed in rural areas (see the bottom panel of Figure 9): for instance, while the fraction of girls surviving to age three increased by 1.4 percentage points more than the corresponding fraction for boys, the difference in the proportion of boys versus girls with height-for-age z-score below -2 decreased by approximately 5 percentage points.

\subsection{Looking for Factors Driving the Changes in Nutritional Status}

In the previous sections we have examined if changes in child mortality or migration patterns from rural to urban areas can mechanically explain at least part of the trends described in Section 4, and we have argued that this does not appear to be the case. In this section we attempt to evaluate how much of the changes can be explained, first, by changes over time in the distribution of economic and demographic factors that are likely to be important predictors of child nutritional status and, second, by changes in the "returns" of these factors on child nutrition. For the first purpose, we use an approach borrowed from DiNardo, Fortin, and Lemieux (1996), which is a semiparametric analogue to the more familiar Oaxaca decomposition for linear regression models (Oaxaca (1973)). Namely, given the cumulative distribution function $F(z)$ of an anthropometric index $z$, and letting $\mathbf{x}$ denote a vector of predictors, we estimate a counterfactual distribution of $z$ for 1998-99 using the conditional distribution $F(z \mid \mathbf{x})$ in 1992-93 and $F(\mathbf{x})$ in 1998-99. On the one hand, this semiparametric approach has the advantage of analyzing changes in the whole distribution, but on the other hand its non-parametric nature is not easily adapted to studying changes in the conditional

relation between child nutrition and its predictors. Hence, for this second purpose in Section 5.4 we make use of conventional Oaxaca decompositions, and we shift focus from the whole distribution to the more limited analysis of the probability of stunting and wasting.

The list of predictors of child nutritional status that we use includes a series of variables measured at the child, household and village level. We exclude variables such as housing characteristics, labor supply and asset ownership (the NFHS does not include information on expenditure or income). Even though these latter variables are likely to be good predictors of child nutritional status, they are certainly endogenous, as they are largely determined jointly with expenditures for child nutrition and health care. We include a polynomial in age to capture the very strong 
association between age and z-scores (see Figure 1). This allows to evaluate if part of the change in the distribution of z-scores is simply due to a change in the age distribution of children. Father and (especially) mother's education have been widely documented as important determinant of child health (e.g. see Drèze and Sen (2002), Ch. 7, and references therein). Mother's schooling is categorized with dummies for mother illiterate (omitted), mother literate below middle school, completed middle school, and high school and above. Father's education level is categorized as no schooling (omitted), primary completed, secondary completed, or higher than secondary. Due to the limited scope of the land market in India, we can also use a dummy for land ownership as an exogenous predictor. ${ }^{15}$ The household demographic structure is taken into account by including household size and a dummy for high birth order set to be equal to one for children with more than three older siblings. Among the household characteristics we also include religion (dummies for Muslim and "other religions", with Hindu category omitted) and a binary variable equal to one when the household head is a woman. Information on caste is included in both surveys but we choose not to use it because definitions are not consistent between the two questionnaires. Finally, for children living in rural areas, we use a set of indicators for community characteristics. These village-level variables are only available for the rural sample, for which both surveys also include a 'village questionnaire'. In our choice of community characteristics we are limited by a number of non-comparability issues due to differences in the variables included in the village questionnaire of the two surveys. Ultimately, we are left with the use of a list of binary variables equal to one if the following are present in the village: electrification, Fair Price Shop, no drainage, Anganwadi, Mahila mandal, pharmacy, Health Sub-centre and Primary Health Center. ${ }^{16}$ The inclusion of measures of health facilities may be important in explaining changes in child nutritional status. For instance, Deolalikar (2005) stresses the role that increased government spending on health and nutrition program should have in reaching targets of reduced malnutrition and child mortality in India. ${ }^{17}$ It should be noted that the use of community variables has the drawback of leading to a reduction in the rural sample size, as in both surveys several observations are missing, and in the 1992-93 we lose some villages for which the village questionnaire cannot be matched to the individual data. Overall, missing data lead to the loss of approximately 16 percent of the rural

\footnotetext{
${ }^{15}$ We do not use the information on land cultivated and irrigated included in the two NFHS waves as these variables are recorded differently in the two surveys. Moreover, while land ownership can often be assumed to be exogenous in India, it is less clear that this assumption can be used for land cultivated and irrigated.

${ }^{16}$ Fair Price Shops are special retail shops where subsidized staples offered through the Indian Public Distribution System can be purchased by eligible households; Anganwadis are child care centers which operate as the focal point for the delivery of services at the community level to children below six years of age, pregnant and nursing mothers, and adolescent girls; Mahila Mandals (women's club) are village women associations that also have the purpose of sharing health knowledge among members; Primary Health Centers are local health centers that also supervise the operation of more Subcentres, which serve a smaller number of families.

${ }^{17}$ Note, however, that recent research has carefully documented how the existence of health structures is far from sufficient to guarantee the provision of effective health services. See, e.g. Duflo, Banerjee, and Deaton (2004), Das and Hammer (2005).
} 
sample in NFHS-I, and 7 percent of the rural sample in NFHS-II.

We turn now to the description of the estimation of the counterfactual distributions. We describe the estimation for the case where the covariates $\mathbf{x}$ are continuous, but with a change of notation the argument can be straightforwardly adapted to the case where some of the covariates are discrete. Formally, let $f(\bar{z} \mid t)$ be the true density of the anthropometric index $z$ evaluated at $\bar{z}$, in wave $t$, where $t=I, I I$. The density can be rewritten as

$$
f(\bar{z} \mid t)=\int f(\bar{z} \mid \mathbf{x}, t) f(\mathbf{x} \mid t) d \mathbf{x}
$$

where $f(\mathbf{x} \mid t)$ is the density of the covariates $\mathbf{x}$ in wave $t$. For notational convenience, let us write $f(\bar{z} \mid t) \equiv f\left(\bar{z} \mid t_{\mathbf{x}}=t, t_{z \mid \mathbf{x}}=t\right)$, where $t_{z \mid \mathbf{x}}$ indicates the wave that identifies the conditional distribution of $z$ given $\mathbf{x}$, and $t_{\mathbf{x}}$ indicates the wave that identifies the marginal distribution of $\mathbf{x}$. Clearly, the two waves coincide in the actual density. We are interested in studying how much of the changes in the distribution of z-scores can be explained by changes in the distribution of the covariates, keeping the distribution of $z$ conditional on $\mathbf{x}$ constant. In other words, we want to estimate the counterfactual density $f\left(\bar{z} \mid t_{\mathbf{x}}=I I, t_{z \mid \mathbf{x}}=I\right)$. A straightforward way to estimate this object follows after noting that it can be usefully rewritten as follows:

$$
f\left(\bar{z} \mid t_{\mathbf{x}}=I I, t_{z \mid \mathbf{x}}=I\right)=f(\bar{z} \mid t=I) E[R(\mathbf{x}) \mid \bar{z}, t=I]
$$

where

$$
R(\mathbf{x})=\frac{P\left(t_{\mathbf{x}}=I I \mid \mathbf{x}\right) P\left(t_{\mathbf{x}}=I\right)}{P\left(t_{\mathbf{x}}=I \mid \mathbf{x}\right) P\left(t_{\mathbf{x}}=I I\right)}
$$

The proof follows from a straightforward application of the properties of probabilities. The function $R(\mathbf{x})$ is a 'reweighting function' that maps the conditional density from wave $I$ into the counterfactual density $f\left(\bar{z} \mid t_{\mathbf{x}}=I I, t_{z \mid \mathbf{x}}=I\right)$, by increasing (decreasing) the contribution to this counterfactual marginal density of the conditional density $f\left(\bar{z} \mid \mathbf{x}, t_{z \mid \mathbf{x}}=I\right)$ for values of $\mathbf{x}$ that are relatively common (rare) in wave $I I$. The different components of the reweighting function are estimated pooling together data from both NFHS waves. Then the unconditional probability $P\left(t_{\mathbf{x}}=I\right)$ can be simply estimated as the (weighted) fraction of observations that belongs to the first wave, while the conditional probability $P\left(t_{\mathbf{x}}=I I \mid \mathbf{x}\right)$ can be interpreted as the probability that an observation with covariates equal to $\mathbf{x}$ belongs to the second NFHS wave, and it can be estimated using a binary dependent variable model.

The counterfactual density can then be estimated using a simple two-step procedure: first an estimate of $\hat{R}(\mathbf{x})$ is obtained and then the counterfactual density is estimated using a modified nonparametric kernel density estimator as in the following expression

$$
\hat{f}\left(\bar{z} \mid t_{\mathbf{x}}=I I, t_{z \mid \mathbf{x}}=I\right)=\sum_{i \in I} w_{i} \hat{R}\left(\mathbf{x}_{i}\right) \frac{1}{h} K\left(\frac{\bar{z}-z_{i}}{h}\right),
$$

where $w_{i}$ is the sampling weight for the $i^{t h}$ observation (normalized so that $\sum_{i \in I} w_{i}=1$ ), $K($.$) is$ a standard kernel, $h$ is the bandwidth and $i \in I$ indicates that the summation is taken only over 
observations that belong to the first wave. Once the densities have been estimated, the cumulative distribution functions can be calculated as usual by numerical integration. ${ }^{18}$

For the sake of brevity, here we only report the results for all Indian states (excluding as usual Phase I states). We show the resulting predicted changes by sector in Figures 12 and 13. For both sectors, we present four different lines: the actual change, the change in the distribution predicted by the sole change in the distribution of demographic variables (age, household size, and high birth order), the change predicted by the sole change in parental education, and finally the predicted change estimated including all predictors (as we explained above, land ownership and the village amenities are only included in the rural sector).

A few conclusions emerge. First, in all cases the change in the age distribution and other demographic variable predict virtually no improvement in child nutritional status, so that the observed changes are not the result of a mere change in the distribution of child age. Second, even with the inclusion of all predictors, the improvements in short term nutritional status (weight-forheight) are left largely unexplained in both sectors for boys, and in urban areas for girls. Only in the case of girls living in rural areas, and for z-scores below -2 , the actual change is very close to the prediction. Overall, parental education accounts for much of the predicted change in weight-forheight, and the addition of other regressors does not change substantially the results. Third, the predictors are relatively more useful in explaining the change in long-term nutritional status (heightfor-age). This is probably not surprising, as short term nutritional status can be rapidly affected by short term factors that are unlikely to be captured by our predictors. In urban areas, the changes in height-for-age predicted by improvements in parental schooling are fairly similar to the actual ones, which are however larger for low z-scores. The inclusion of the complete set of predictors leaves the results almost unaffected. In rural areas, changes in parental education as well as changes in all included variables predict a small improvement in girl height performances. This contrasts with the small worsening observed instead in the data. The actual small improvement in boy height-for-age is very close to the change predicted by the increase in parental education. However, the inclusion of community variables among the predictors, unlike for girls, increases the predicted decline in the cdf by approximately one percentage point for all negative z-scores. Interestingly, in both rural and urban areas our prediction exercise forecasts much larger improvements for boys than for girls, suggesting that at least part of the gender gap in the changes in nutritional status over time may be due to an association between growth performance and predictors that is stronger for boys than for girls.

\footnotetext{
18 In principle, one can estimate directly the counterfactual CDFs' using a procedure analogous to that just described (see Tarozzi (2005) for details). We choose to estimate the densities first because the resulting graphs are much smoother.
} 


\subsection{Oaxaca Decompositions}

On the one hand, part of the discrepancy between predicted and actual changes documented in the previous subsection is certainly due to the relatively short list of predictors included in our analysis. On the other hand, our results suggest that changes in the distribution of z-scores conditional on the predictors is likely to have changed over time. The semi-parametric approach used so far has the advantage of analyzing changes in the whole distribution, but its non-parametric nature is not easily adapted to studying changes in the conditional relation between child nutrition and its predictors. Hence, for this second purpose we make use of conventional Oaxaca decompositions (Oaxaca (1973)) applied to the analysis of the probability of stunting and wasting, which we estimate with linear probability models. We choose to use a linear probability model even if the dependent variable is binary because a linear model makes the decomposition results easier to interpret. Moreover, the slopes estimated with linear probability models are usually very close to the marginal effects routinely estimated for binary dependent variable models such as logit or probit. ${ }^{19}$

The use of Oaxaca decompositions allows us to examine how the contribution of different factors to boy and girl nutritional status is changing over time in different geographical areas. In Section 4 we showed that the gender differences in changes over time are particularly striking in rural areas of North and East India. For this reason, and to save space, here we pool together North and East, and we restrict our analysis to the rural sector, which also account for the majority of the population, and where the extent of stunting and wasting is larger than in urban areas. Results for the urban sector are available upon request.

Let $D_{i g s}^{z}$ denote a dummy equal to one if the z-score of child $i$, of gender $g, g=m, f$, measured in survey $s, s=I, I I$ is below -2 . Let $X_{i g s}$ denote the vector of determinants of child nutritional status. Then, the model for a given gender and wave is

$$
D_{i g s}^{z}=X_{i g s}^{\prime} \beta_{g s}+\epsilon_{i g s}
$$

so that the change in means over time can be decomposed as:

$$
\begin{aligned}
\bar{D}_{g I I}^{z}-\bar{D}_{g I}^{z} & =\bar{X}_{g I I}^{\prime} \hat{\beta}_{g I I}-\bar{X}_{g I}^{\prime} \hat{\beta}_{g I} \\
& =\left(\bar{X}_{g I I}-\bar{X}_{g I}\right)^{\prime} \hat{\beta}_{g I}+\bar{X}_{g I I}^{\prime}\left(\hat{\beta}_{g I I}-\hat{\beta}_{g I}\right) .
\end{aligned}
$$

The first term in (3) can be interpreted as the part of the change in the mean of the dependent variable associated to a change in the means of the regressors, while the second term is the part due to a change in the coefficients. ${ }^{20}$ The comparison of the first term with the actual change in the mean value of the dependent variable is an exercise analogous to the analysis in Section 5.4, but performed only for the cdf evaluated at -2 .

\footnotetext{
${ }^{19}$ See Nielsen (1998) for a decomposition technique appropriate for logit models.

${ }^{20}$ Note that even if the two components, by construction, have to sum up to the change in the mean dependent variable, their signs may differ, so that the fraction of the change associated to each component is not constrained to be bounded between zero and one.
} 
We report the results of the decompositions in Tables 9 to 12. Each table includes separate decompositions for males and females for a given geographical area and anthropometric index. For each gender, the first four columns display the estimated coefficients of the linear probability model and the corresponding t-ratios. For the $i^{\text {th }}$ predictor, the fifth column reports $\Delta_{X_{i}} \equiv$ $\left(\bar{X}_{i, g I I}-\bar{X}_{i, g I}\right) \hat{\beta}_{i, g I}$, that is, the change in the probability of stunting (or wasting) predicted by the change in the mean value of the predictor, keeping the estimated coefficient equal to its value in 1992-93. The figures in the last column represent instead $\Delta_{\beta_{i}} \equiv \bar{X}_{i, g I I}\left(\hat{\beta}_{i, g I I}-\hat{\beta}_{i, g I}\right)$, that is, the change predicted by the shift in the estimated coefficients. Each regression also includes (not shown) a constant and a cubic in age and household size. For each decomposition, we also report the total change predicted by the change in the mean value of the predictors and the total change predicted by the change in coefficients. By construction, the sum of the two changes (denoted 'total changes' in the tables) is equal to the change over time in the proportion of children with z-score below -2 . Finally, below these total changes, we calculate the changes predicted based on subsets of regressors. Namely, the three maternal education dummies ('M. Educ.' in the tables), the three paternal education dummies ('F. Educ.'), and the variables that measure the availability of health-related amenities in the village ('Health Amen.'). Note that, even though the regressions do not include variables such as income or asset ownership (which are certainly endogenous because determined jointly with child health inputs) one should be very cautious in interpreting the regression results in a causal way. Most of the included regressors are in fact likely to be correlated with unobserved heterogeneity in preferences, cultural norms, or other locationspecific characteristics that may also have a direct impact on the dependent variable. Similarly, endogenous placement of village amenities such as health structures or Fair Price Shops can further hinder the causal interpretation of the corresponding coefficients. For these reason, we think that the interest of these results lie more in their descriptive content than in their causal meaning, which is at best doubtful.

Table 9 shows the decomposition results for weight-for-height in rural North-East. The proportion of boys with z-scores below -2 shows a large decline (from 21.6 to 15.4 percent), while the improvement for girls is much smaller (from 16.8 to 15.4 percent). Overall, the included predictors explain only a small fraction of the total variation in the dependent variable, as in all regressions the $R^{2}$ remains below 0.05 . Also, most coefficients are not statistically different from zero at standard levels. This is perhaps not too surprising, as weight-for-height is an indicator of short term nutritional indicator, and hence is more likely than height-for-age to depend on temporary factors that are not captured by our predictors. This may also explain why several coefficients appear to have erratic magnitude and sign. However, some general patterns can be identified. Overall, for both boys and girls the change in the level of parental schooling only marginally affects the prevalence of wasting. However, the change in the paternal schooling coefficients reduces the proportion of wasting for boys by 1.7 percentage points, while reducing the proportion for girls by twice as much. 
Interestingly, increased availability of village health amenities contribute to a large reduction in wasting for boys $\left(\Delta_{X}=-0.013\right)$, while it contributes to an increase (albeit very small) for girls $\left(\Delta_{X}=0.0013\right)$. The presence of Fair Price Shops - where selected staples can be purchased at subsidized prices by eligible households - is consistently associated with lower levels of wasting, even if the coefficients are never significant, and their magnitude decreases between the two surveys. High birth order always enters the regressions with a positive sign, but it has virtually no relevance for boy wasting. For girls, the coefficient is very close to zero in 1992-93, but it becomes much larger (0.02) and almost significant at a 10 percent level in the later survey. Overall, the changes in the regressors predict a 1.6 percent decline in wasting for boys, and only a 0.2 percent decline for girls. The change in the coefficient also largely contribute to the increase in the gender gap, as the predicted decline in wasting is only one percent for girls, but four times as large for boys.

In rural South (Table 10), the included predictors explain a much larger proportion of the variation in the dependent variable, and the $R^{2}$ of each regression is at least 0.06 . Notice that for this index of nutritional status even in the South we observe a movement towards 'boy advantage', as wasting decreases from 22.1 to 20.1 percent of boys, while it increases from 20 to 21.6 percent for girls. This is consistent with the result in the top right panel of Figure 10, which showed negative differences-in-differences (even if small and not statistically different from zero) for z-scores below -1 . Looking at parental education, we note that $\Delta_{\beta}$ for father's education - in contrast with the North - contributes to a large decline of wasting among boys (-0.046), while the contribution is negligible for girls. Interestingly, the maternal returns to education decrease considerably for girls (but not for boys), so that the sum of the $\Delta_{\beta_{i}}$ for the maternal schooling dummies increases wasting by 6 percent. As for the North-East, wasting is less prevalent in villages where a Fair Price Shop is present, but less so in the more recent survey. One important difference with the patterns observed in the North-East is that village health structures appear to have benefitted more girls than boys. The change in availability itself contributes only marginally to the change in the mean dependent variable, but the sum of the corresponding $\Delta_{\beta_{i}}$ is equal to 0.085 for boys, and to 0.017 for girls. The very large negative contribution for boys is almost completely counterbalanced by a change in the coefficient for electrification, which goes from predicting a 2.4 increase in wasting in 199293 to predicting a 6 percent decrease in 1998-99 (both coefficients are, however, very imprecisely measured). Overall, our reading of these results is that the gender and area specific results for wasting do not seem to offer a very coherent explanation of why we observe the large gender differences in distributional changes over time described in Section 4.

In Table 11 we examine the decompositions for the rural North-East of the change in stunting. The proportion of stunted children decreases from 52.9 to 51.8 percent for boys, while it increases from 51.1 to 54.6 among girls. The $R^{2}$ show that the regressors predict a much larger fraction of the variance of the dependent variable than for weight-for-height. This is again consistent with the fact that height-for-age is a measure of long-term nutritional status, and hence it is less 
influenced than weight-for-height by short term factors unlikely to be captured by the household and community characteristics included in the analysis. For both boys and girls, maternal schooling is strongly associated with lower levels of stunting, and in both waves higher schooling leads to larger reductions. Moreover, the magnitude of the coefficients is always larger in 1998-99 than in 1992-93: for instance, in NFHS-I a boy whose mother has completed middle school (high school or above) has a 7.8 (15.8) percent smaller probability of being stunted than if he had an illiterate mother, and the reduction becomes 13.5 (24.1) in 1998-99. Similar patterns emerge for girls, even if in every single case mother's education is associated with a larger reduction in stunting for boys than for girls. In particular, the coefficient for mother having a middle school diploma is less than half as for boys, in both surveys. Overall, there is a 0.8 percent predicted decline in stunting among boys due to increases in maternal education, to which a further 1.2 percent decline is added due to the increased magnitude of the coefficients. For girls, the two figures are respectively equal to 0.3 and 1.5 percent. Overall, then, maternal education does not appear to have benefited boys disproportionately in North-East India. There is some evidence instead that this has been the case for father's education. The estimated sum of $\Delta_{X_{i}}$ is small, and approximately equal to 0.7 for both genders, but while the coefficients for boys contribute to an overall reduction of 3.3 percent in stunting among boys, the change for girls is very small (0.3) and positive. A large contribution to the gender difference in the change in the extent of stunting between the two surveys comes from the health-related community variables. First, the change in their availability predicts an overall a 1.8 percent decline in stunting for boys, but only a 0.1 percent drop for girls. Second, the change in the corresponding coefficients sums up to a 1.2 increase in stunting among girls, while it predicts an almost 3 percent decline for boys. Looking at all regressors, the change in their mean value predicts large improvements for boys (-0.046) and small gains for girls (-0.003). In these geographical areas, we found a qualitatively similar result for weight-for-height. However, while the changes in the slopes predicted further improvements in short-term nutritional status (again more so for boys), in the case of height-for-age the changes dampen the improvements predicted by the sole changes in covariates, marginally more so for girls than for boys.

In the South (Table 12), the fraction of stunted children decreases from 39.8 to 37.8 for boys, while it decreases more for girls, from 43.5 to 39.8 percent. As in North-East India, maternal education is strongly negatively associated with stunting, but in the South there is evidence of a strong increase in the 'returns' to mother's schooling only for girls whose mothers have at least a middle school diploma. The change in maternal schooling leads to similar predicted improvements between genders (a 2 percent decline in stunting for boys, and a 1.7 percent decline for girls), but the change in the slopes, while leaving stunting almost unaffected for boys, decreases it by 3.2 percentage points for girls. Increases in father's education predict less stunting for both boys and (even more so) girls, but while the sum of the corresponding $\Delta_{\beta_{i}}$ further reduces stunting by 1.8 percentage points, it increases the fraction of girls with low height by 8 percentage points. This 
latter result for girls is almost perfectly balanced by a much larger negative association between stunting and village electrification in the second round of the NFHS. The contribution of community characteristics is somewhat difficult to explain. On the one hand, the change in the level of the regressors predicts a 1.5 percent decline is stunting for boys, and almost zero decline for girls (a results very similar to what we observed in North-East), but the coefficient changes sum up to a 2 percent increase in stunting for girls, and a 20 percent increase for boys, almost completely explained by the change in the coefficients for availability in the village of drainage, Anganwadis, and Mahila Mandals. Notably, while the presence of an Anganwadi is associated with a 7 percent decline in boy stunting in 1992-93 (significant at 5 percent level), the coefficient becomes even larger but of opposite sign (but not significant) in 1998-99. Note, however, that this very large figure (20 percent) is more than compensated by a sizeable increase in magnitude of the negative coefficient that relates stunting to village electrification. Overall, the decline in stunting predicted by the change in the covariates is very similar between genders ( $\Delta_{X}$ is - .037 for boys, and -.042 for girls). Most of the difference (in favor of girls) arises from the changes in the slopes, which almost average out to zero for girls $\left(\Delta_{\beta}=0.005\right)$, while downplaying the reduction in stunting for boys $\left(\Delta_{\beta}=0.017\right)$.

\section{Conclusions}

The Indian National Accounts show rapid rates of GDP growth during the 1990s. Estimates on the reduction in poverty during this decade are not unanimous, but according to several researchers poverty declined considerably, especially in urban areas. In this paper we use data from two independent cross-sectional surveys (completed in 1992-93 and 1998-99) to evaluate to what extent the growth observed during the 1990s has been associated with a reduction in malnutrition among children of age 0 to 3 . We find that measures of short-term nutritional status based on weight given height show large improvements, especially in urban areas. For instance, we estimate that the proportion of children categorized as 'wasted' (that is, whose weight given height is such that the $\mathrm{z}$-score is below -2 ) decreased by approximately 3 percentage points in rural areas, and by 5 percentage point in urban areas. The results for height-for-age, a measure of long-term nutritional status, are more mixed, and we only find improvements in urban areas, where the proportion of 'stunted' children (that is, with z-score below -2) decreased by approximately three percentage points between 1992-93 and 1998-99. However, we also document that these figures hide large differences between genders and across different geographical areas. In fact, we find that gender inequality in nutritional status increased, with nutritional status improving substantially more for boys than for girls. We also document the existence of apparent geographical differences in these changes: the gender differences in the changes in nutritional status are particularly striking in rural areas of North and East India, areas where the existence of widespread son preference has been 
documented by an immense body of research.

We also make a first attempt at evaluating the determinants of the changes over time, studying the relation between changes in child nutritional status and changes over time in a list of economic and demographic variables that should be strongly associated with child growth performance. Overall, we find that changes over time in the level of the predictors explain a sizeable fraction of the overall change in the distribution of height-for-age z-scores, while the improvements in weightfor-height remain largely unexplained. Oaxaca decompositions of the probability of stunting and wasting confirm that for both genders, and across all of India, most of the change in anthropometric performances is explained by changes in the regression coefficients that relate the z-scores to the predictors, rather than by changes in the predictors themselves. However, a detailed analysis of the patterns of the changes in the coefficients does not point to a simple explanation for the emerging gender differences we document.

The unequal improvements for boys and girls are all the more difficult to explain because the NFHS suggests that factors such as fertility behavior, women schooling and female labor force participation changed in ways that would suggest a generalized increase in the relative standing of women in the economy and in the Indian society more generally. At the same time, the relative large samples available in the surveys we have used, the result of formal tests of statistical significance, as well as the fact that we do not observe important gender disparities in the changes in the South (where son preference is less pronounced), lead us to think that the results we document are not simply due to sampling error. Unfortunately, our dataset does not allow us to examine directly the possible effect on gender bias in intrahousehold allocation of resources of factors such as male versus female wages, dowries and marriage expenditures, or more generally expected returns to boys versus girls.

It would be useful to corroborate our result with different data sources, and it will be very interesting to study if analogous trends are observed in the third round of the National Family and Health Survey, which at the time of writing is being conducted in the field. Another obvious next step would be to study directly the pathways from poverty reduction to child nutrition outcomes, looking in particular at the possible impact of the recent wave of economic liberalization. 


\section{References}

ABADIE, A. (2002): "Bootstrap tests for distributional treatment effects in instrumental variable models," Journal of The American Statistical Association, 97(457), 284-292.

Agarval et Al. (1991): Growth Performance of Affluent Indian Children (Under-Fives): Growth Standards for Indian Children. Nutrition Foundation of India, New Delhi.

Anderson, S. (2003): "Why Dowries Payments Declined with Modernization in Europe but Are Rising in India," Journal of Political Economy, 111(2), 269-310.

Basu, A. M. (1992): Culture, The Status of Women and Demographic Behaviour. Oxford Clarendon Press.

Basu, A. M. (1999): "Fertility Decline and Increasing Gender Imbalance in India, Including a Possible South Indian Turnaround," Development and Change, 30, 237-263.

Behrman, J. (1988a): "Intrahousehold Allocation of Nutrients in Rural India: Are Boys Favored? Do Parents Exhibit Inequality Aversion," Oxford Economic Papers, 40, 32-54.

Behrman, J., H. Alderman, And J. Hoddinott (2004): "Hunger and malnutrition," Copenhagen Consensus Challenge Paper.

Behrman, J. R. (1988b): "Nutrition, Health, Birth Order and Seasonality: Intrahousehold Allocation among Children in Rural India," Journal of Development Economics, 28, 43-62.

Bhandari, N., R. Bahl, S. Taneja, M. de Onis, and M. K. Bhan (2002): "Growth Performance of Affluent Indian Children is Similar to that in Developed Countries," Bulletin of the World Health Organization, 80(3), 189-195.

Borooah, V. K. (2005): "The Height-for-Age of Indian Children," Economics and Human Biology, 3(1), $45-65$.

Bourne, K., And G. M. Walker (1991): "The Differential Effect of Mothers Education on Mortality of Boys and Girls in India," Population Studies, 45(2), 203-219.

Das, J., And J. Hammer (2005): "Money for nothing. The dire straits of medical practice in Delhi, India," World Bank Policy Research Working Paper 3669.

Das Gupta, M. (1987): "Selective Discrimination Against Female Children in Rural Punjab," Population and Development Review, 13(1).

Das Gupta, M., And M. Bhat (1995): "Intensified gender bias in India: a consequence of fertility decline," WP no. 95.02, Harvard Center for Population and Development Studies.

Dasgupta, P. (1993): An Inquiry into Well-Being and Destitution. Oxford University Press.

Datt, G., V. Kozel, and M. Ravallion (2003): "A Model-Based Assessment of India's Progress in Reducing Poverty in the 1990s," Economic and Political Weekly, pp. 355-361.

DAvidson, R., AND J. Duclos (2000): "Statistical inference for stochastic dominance and for measurement of poverty and inequality," Econometrica, 68(6), 1435-64.

Deaton, A. (2003): "Prices and Poverty in India, 1987-2000," Economic and Political Weekly, pp. 362-368.

Deaton, A., And J. DrÈze (2002): "Poverty and Inequality in India, a Re-Examination," Economic and Political Weekly, pp. 3729-3748, September 7.

Deaton, A., And V. Kozel (2005): "Data and Dogma: The Great Indian Poverty Debate," New Delhi, India, MacMillian. 
Deolalikar, A. B. (2005): "The Millennium Development Goals for India: How Attainable?," in Economic Growth, Economic Performance and Welfare in South Asia, ed. by R. Jha. Palgrave Macmillan, London.

Dibley, M. J., J. B. Goldsby, N. W. Staehling, and F. L. Trowbridge (1987a): "Development of Normalized Curves for the International Growth Reference: Historical and Technical Considerations," American Journal of Clinical Nutrition, 46(5), 736-748.

(1987b): "Interpretation of Z-score Anthropometric Indicators Derived from the International Growth Reference," American Journal of Clinical Nutrition, 46(5), 749-762.

Dinardo, J., N. Fortin, And T. Lemieux (1996): "Labor Market Institutions and the Distribution of Wages, 1973-1992: a Semiparametric Approach," Econometrica, 64(5), 1001-1044.

Drèze, J., AND A. SEn (eds.) (1995): India: economic development and social opportunity. Oxford University Press, Oxford and New Delhi.

edn.

(eds.) (2002): India: development and participation. Oxford University Press, New York, second

Duflo, E., A. Banerjee, and A. Deaton (2004): "Wealth, health, and health services in rural Rajasthan," AER Papers and Proceedings, 94(2), 326-330.

Dyson, T., And M. Moore (1983): "On Kinship Structure, Female Autonomy and Demographic Behaviour in India.," Population and Development Review, 9(1), 35-60.

FAn, J. (1992): "Design-Adaptive Nonparametric Regression," Journal of The American Statistical Association, 87, 998-1004.

Goldin, C. (1995): "The U-Shaped Female Labor Force Function in Economic Development and Economic History," in Investment in Women's Human Capital, ed. by T. P. Schultz. Chicago, University of Chicago Press.

Gorstein, J., K. Sullivan, R. Yip, M. de Onís, F. Trowbridge, P. Fajans, and G. Clugston (1994): "Issues in the Assessment of Nutritional Status Using Anthropometry," Bulletin of the World Health Organization, 72, 273-283.

HARriss, B. (1995): "The intrafamily distribution of hunger in South Asia: selected essays," in The political economy of hunger, ed. by J. Drèze, A. Sen, and A. Hussain. Clarendon Press, Oxford.

Howes, S. (1996): "A new test for inferring dominance from sample data," Discussion paper, STICERD, London School of Economics.

Irudaya Rayan, S., And K. S. James (2004): "Second National Family Health Survey. Emerging Issues," Economic and Political Weekly, pp. 647-651.

Jensen, R. (2002): "Equal Treatment, Unequal Outcomes? Generating Gender Inequality Through Fertility Behavior," Working Paper, JFK School of Government, Harvard.

Klasen, S. (1999): "Malnourished, but Surviving in South Asia, Better Nourished and Dying Young in Africa: What Can Explain this Puzzle?," Sonderforschungsbereich 386 Discussion Paper No. 213. University of Munich.

Klasen, S., And A. Moradi (2000): "The Nutritional Status of Elites in India, Kenya, and Zambia: An Appropriate Guide for Developing Reference Standards for Undernutrition?," Sonderforschungsbereich 386 Discussion Paper No. 217, University of Munich.

Kuczmarski et AL. (2000): "CDC Growth Charts: United States," Advance Data, Center for Disease Control and Prevention, National Center for Health Statistics, (314). 
Maluccio, J. A., J. Hoddinott, J. R. Behrman, R. Martorell, A. Quisumbing, and A. D. Stein (2005): "The Impact of an Experimental Nutritional Intervention on Education into Adulthood in Rural Guatemala," Working Paper.

Martorell, R., and J. P. Habicht (1986): "Growth in Early Childhood in Developing Countries," in Human Growth: a Comprehensive Treatise, ed. by F. Falkner, and J. M. Tanner, vol. 3. Plenum Press, New York.

Miller, B. (1981): The Endangered Sex: Neglect of Female Children in Rural North India. Cornell University Press.

Munshi, K., And M. Rosenzweig (2005): "Why is mobility in India so low? Social Insurance, Inequality, ang Growth," .

Murthi, M., A.-C. Guio, And J. Drèze (1995): "Mortality, Fertility and Gender Bias in India: A District Level Analysis," Population and Development Review, 12(4), 745-782.

NiELSEn, H. S. (1998): "Discrimination and detailed decomposition in a logit model," Economic Letters, 61,115120 .

OAXacA, R. (1973): "Male-Female Wage Differentials in Urban Labor Markets," International Economic Review, 14(3), 693-709.

Rosenzweig, M. R., And P. T. Schultz (1982): "Market Opportunities, Genetic Endowments, and Intrafamily Resource Distribution: Child Survival in Rural India," American Economic Review, 72(4), 803-815.

SAhn, D. E., And D. C. Stifel (2002): "Robust comparisons of malnutrition in developing countries," American Journal of Agricultural Economics, 84(3), 716-735.

Sen, A., And Himanshu (2004): "Poverty and Inequality in India," Economic and Political Weekly, pp. 4247-4263, September 18.

Shrimpton, R., C. G. Victora, M. De Onis, R. C. Lima, M. Blossner, and G. Clugston (2001): "Worldwide timing of growth faltering: implications for nutritional interventions," Pediatrics, 107(5:E75), $1-7$.

Silverman, B. W. (1986): Density Estimation for Statistics and Data Analysis. London and New York, Chapman and Hall.

Sopher, D. E. (1980): "The Geographical Patterning of Culture in India," in An Exploration of India: Geographical Perspectives on Society and Culture, ed. by D. E. Sopher. Cornell University Press, Ithaca, NY.

Strauss, J., K. Beegle, A. Dwiyanto, Y. Herawati, D. Pattinasarany, E. Satriawan, B. Sikoki, Sukamdi, And F. Witoelar (2004): Indonesian living standards: Before and after the financial crisis, RAND Corporation Monograph Series. RAND Corporation, Santa Monica, CA.

Strauss, J., And D. Thomas (1998): "Health, Nutrition, and Economic Development," Journal of Economic Literature, 36(2), 766-817.

Svedberg, P. (2000): Poverty and undernutrition: theory, measurement, and policy. Oxford University Press, Oxford, UK.

TArozzi, A. (2005): "Calculating Comparable Statistics from Incomparable Surveys, with an Application to Poverty in India," Forthcoming, Journal of Business and Economic Statistics.

Topalova, P. (2005): "Trade liberalization, poverty and inequality: evidence from Indian districts," NBER Working Paper 11614. 
Waterlow, J. C., R. Buzina, W. Keller, J. M. Lane, M. Z. Nichaman, and J. M. Tanner (1977): "The Presentation and Use of Height and Weight Data for Comparing the Nutritional Status of Groups of Children Under the Age of 10 Years," Bulletin of the World Health Organization, 55(4), 489-498.

WHO Working Group (1986): "Use and Interpretation of Anthropometric Indicators of Nutritional Status," Bulletin of the World Health Organization, 64(6), 929-941.

World Health Organization (1995): The world health report 1995. Bridging the gaps. Geneva.

Yamaguchi, K. (1989): "A Formal Theory for Male-Preferring Stopping Rules of Childbearing: Sex Differences in Birth Order and in the Number of Siblings," Demography, 26, 451-465. 


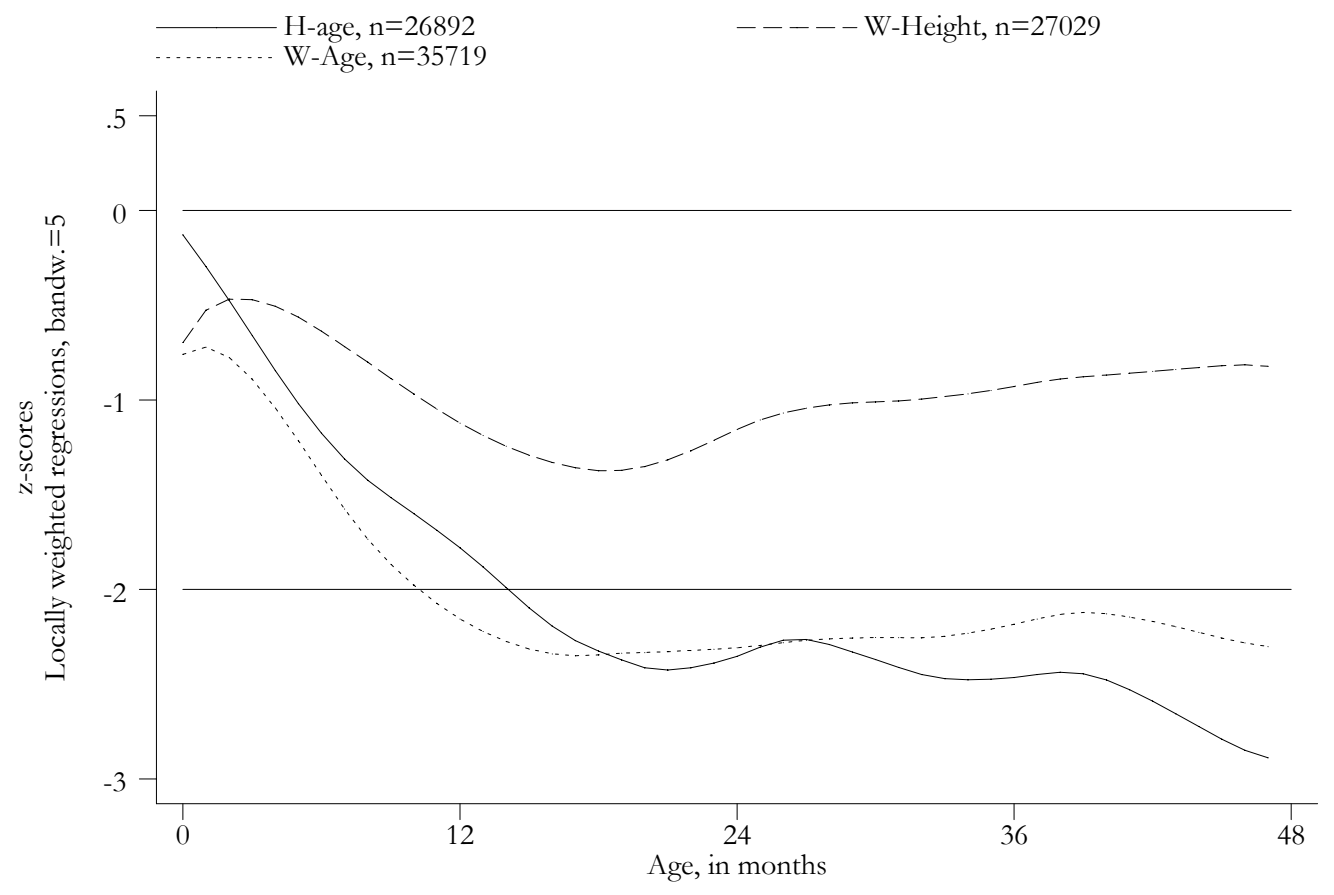

Figure 1: Source: authors calculations from NFHS-I (1992-93). Z-scores for weight-for-age are for Indian states, rural and urban areas, while z-scores for height-for-age and weight-for-height exclude Phase I states (Andhra Pradesh, West Bengal, Himachal Pradesh, Madhya Pradesh, and Tamil Nadu), for which height is missing.
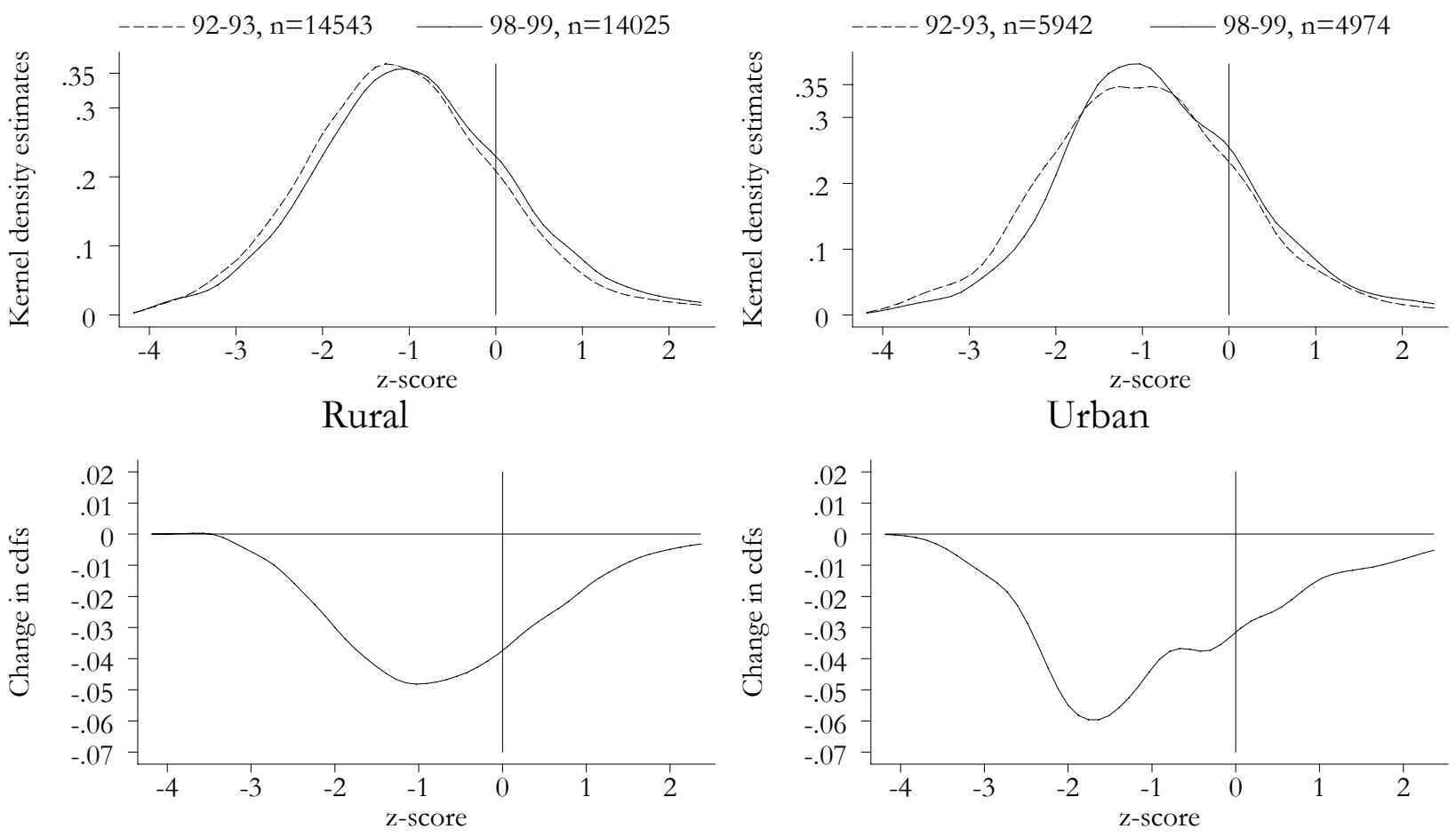

Rural

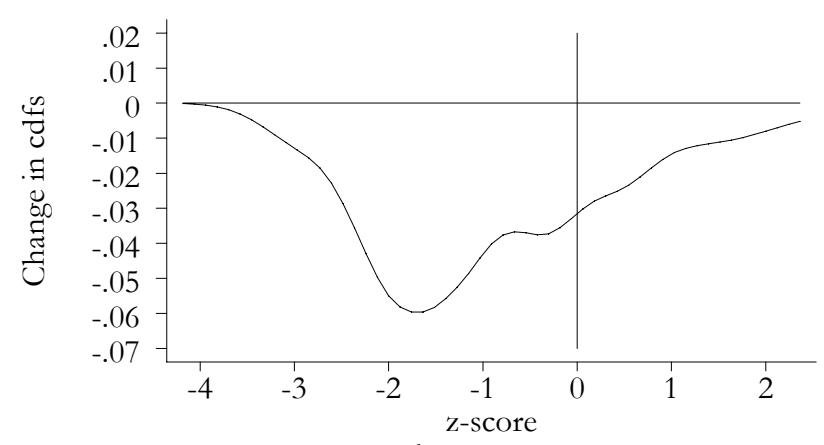

Urban

Figure 2: Weight-for-height, both genders, age 0-3 years, no Phase I states. 

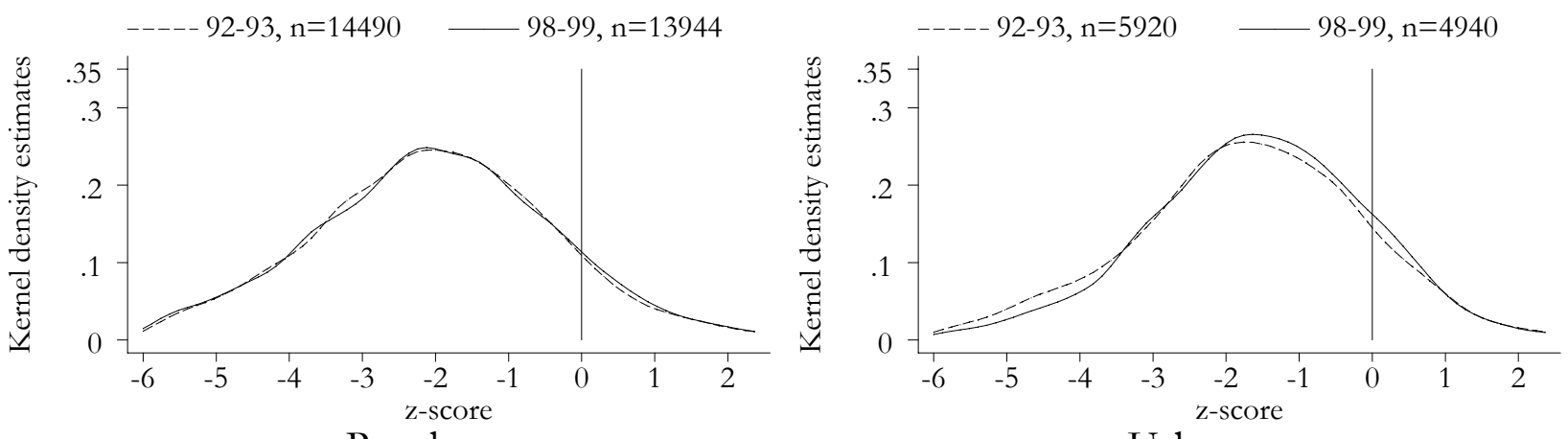

Rural
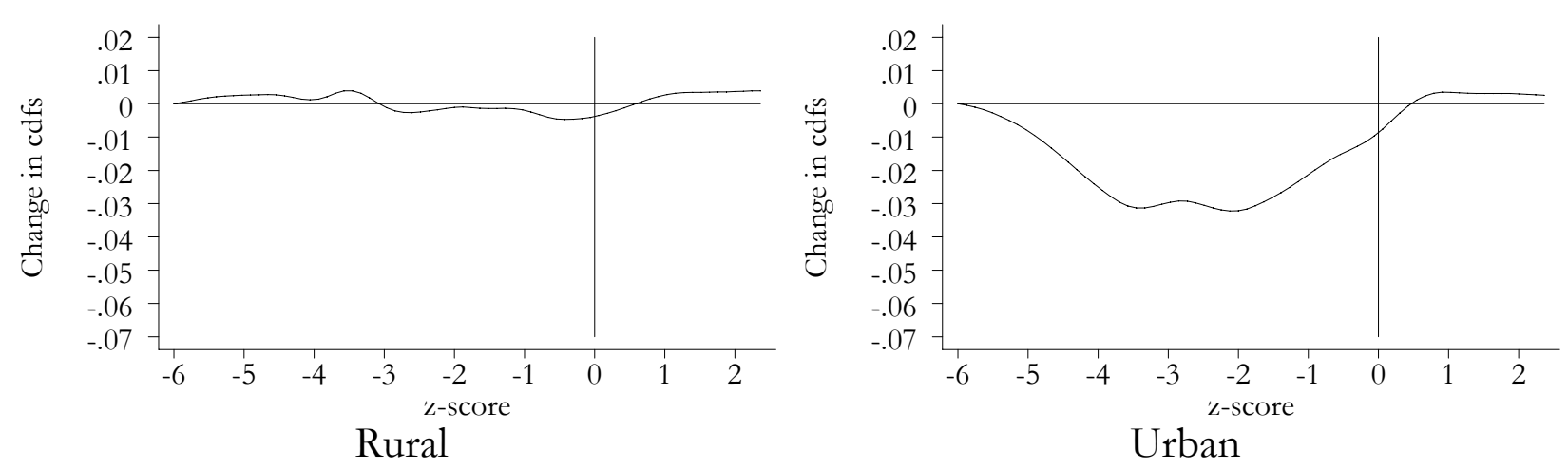

Figure 3: Height-for-age, both genders, age 0-3 years, no Phase I states.
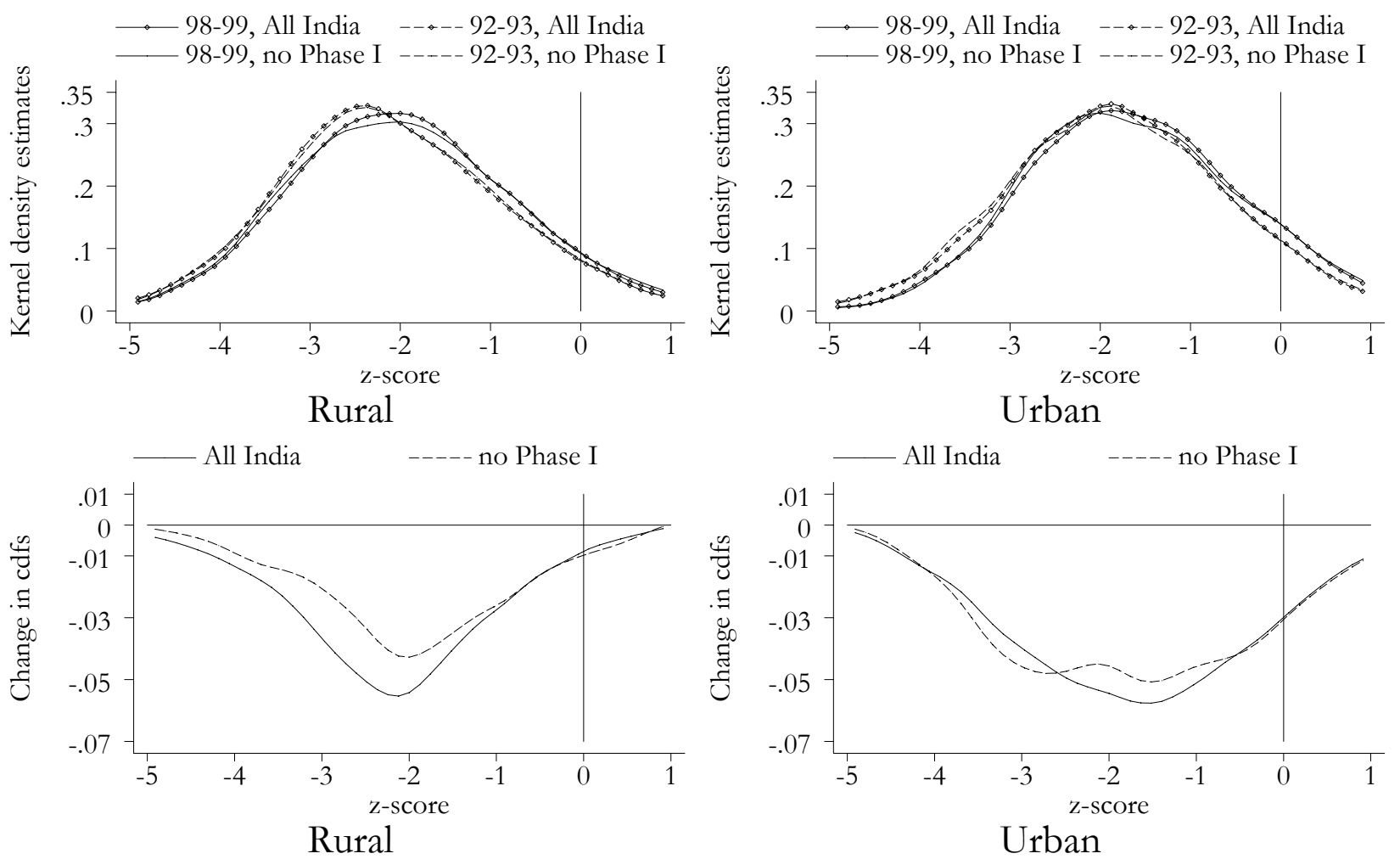

Figure 4: Weight-for-age, both genders, age 0-3 years. All India vs all India excluding states with no height in NFHS-I. 

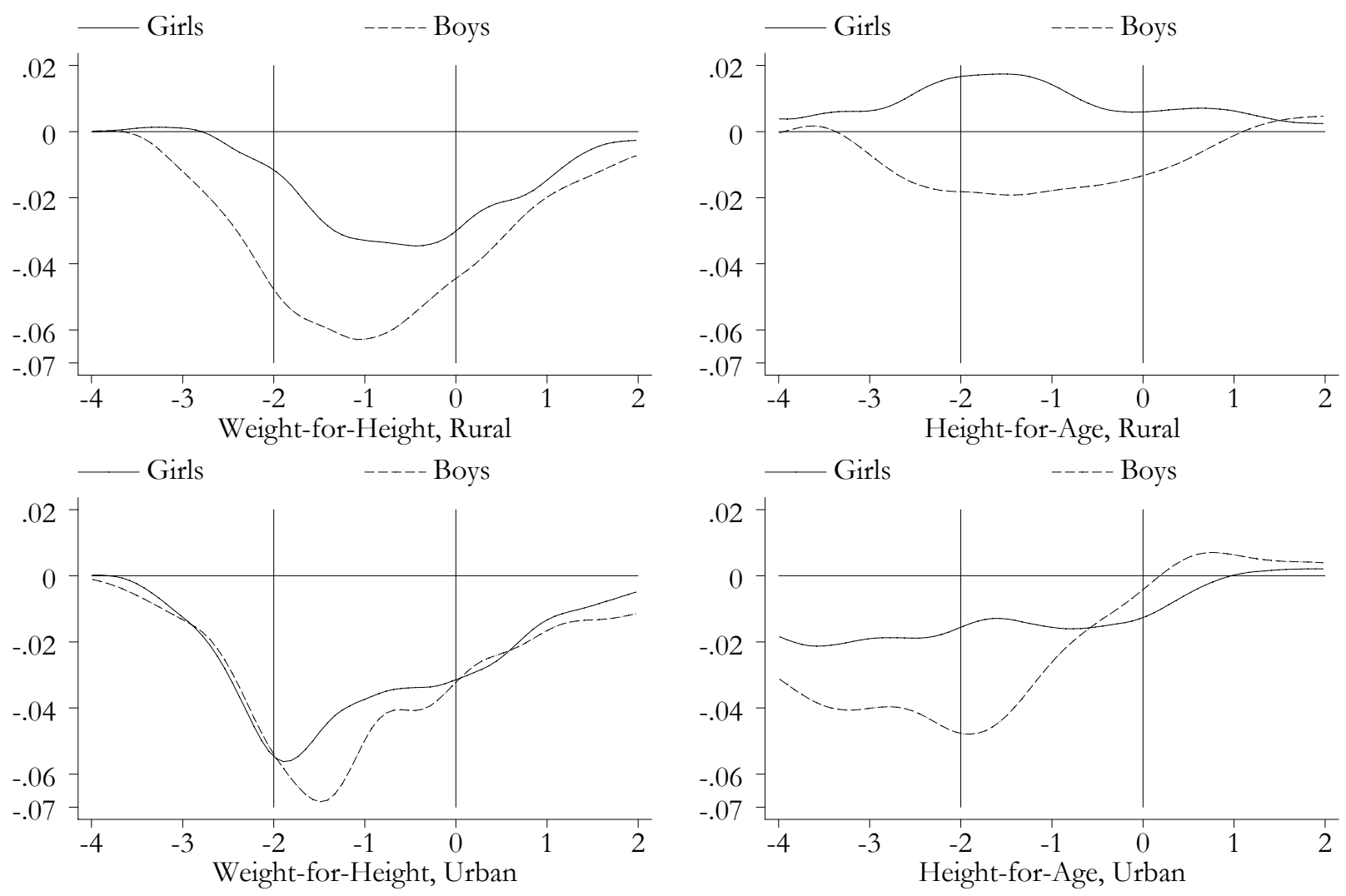

Figure 5: Change in nutritional status over time. Source: authors' calculations from NFHS-I and NFHS-II. All India excluding Andhra Pradesh, West Bengal, Himachal Pradesh, Madhya Pradesh, and Tamil Nadu. Each line is calculated as $F_{I I}(z)-F_{I}(z)$. 

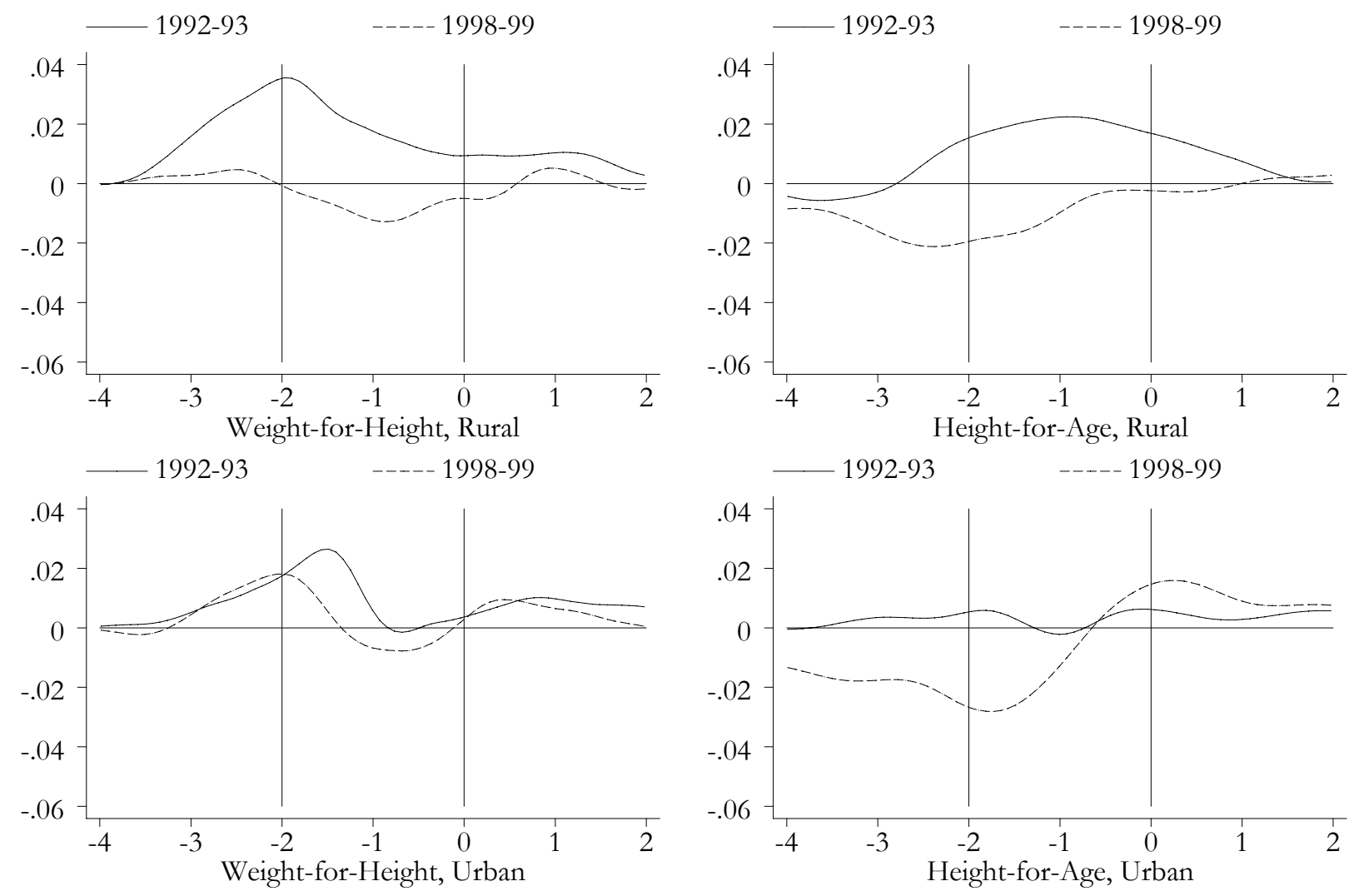

Figure 6: Gender differences in nutritional status. Source: authors' calculations from NFHS-I and NFHS-II. All India excluding Andhra Pradesh, West Bengal, Himachal Pradesh, Madhya Pradesh, and Tamil Nadu. Each line is calculated as $F_{\text {boys }}(z)-F_{\text {girls }}(z)$. 


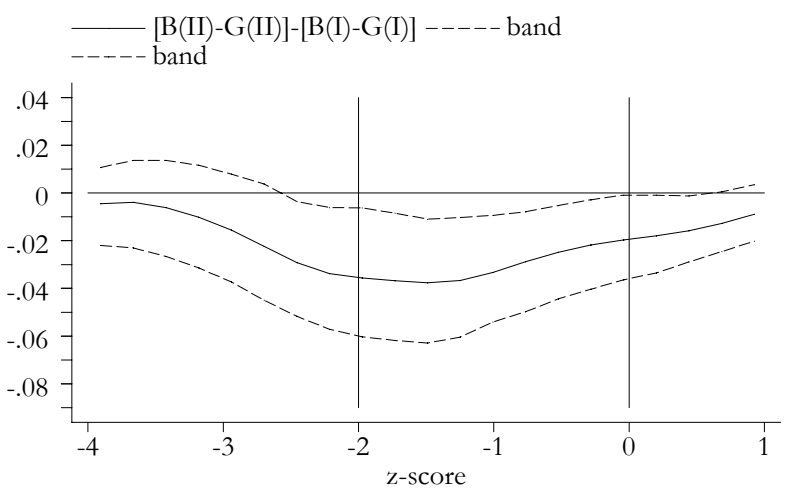

Height-for-age, Rural sector

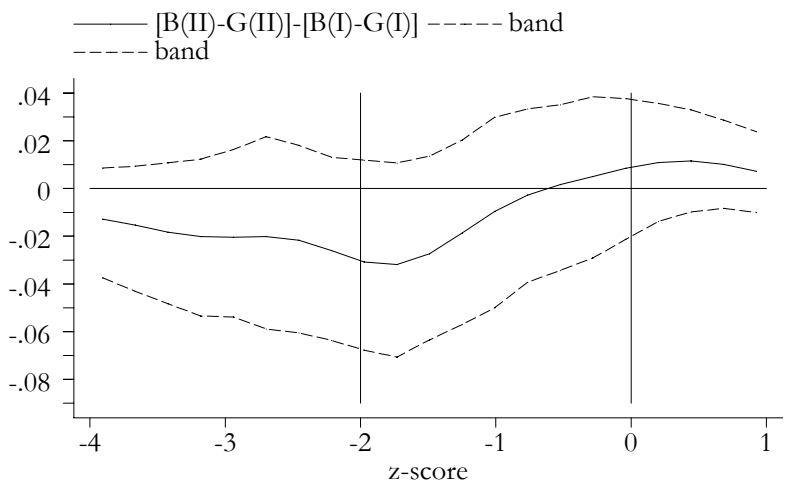

Height-for-age, Urban sector

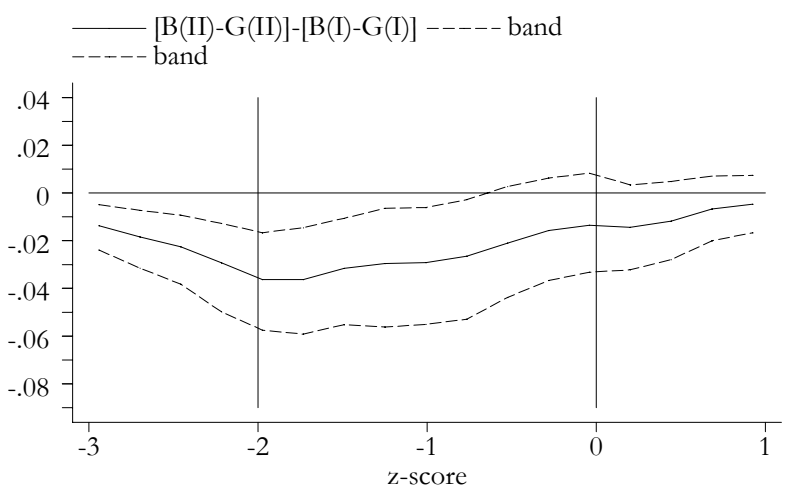

Weight-for-Height, Rural sector [B(II)-G(II)]-[B(I)-G(I)]----- band
band

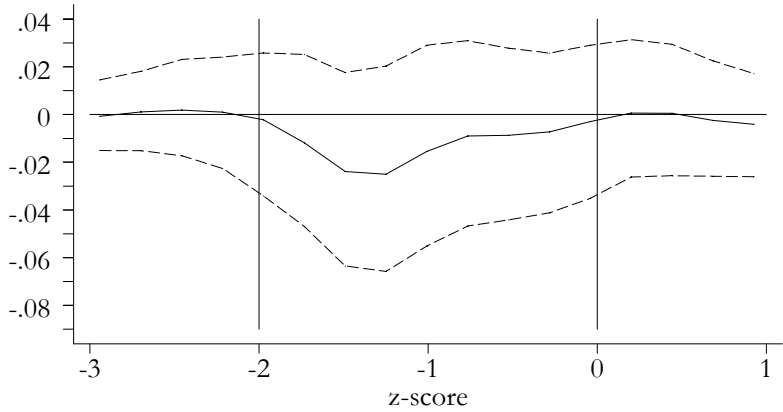

Weight-for-Height, Urban sector

Figure 7: Change over time of gender differences in nutritional status. Source: authors' calculations from NFHS-I and NFHS-II. All India excluding Andhra Pradesh, West Bengal, Himachal Pradesh, Madhya Pradesh, and Tamil Nadu. Each continuous line represents the change over time of the pointwise gender difference in distributions. The dashed lines represent $95 \%$ confidence bands (see text for details). 


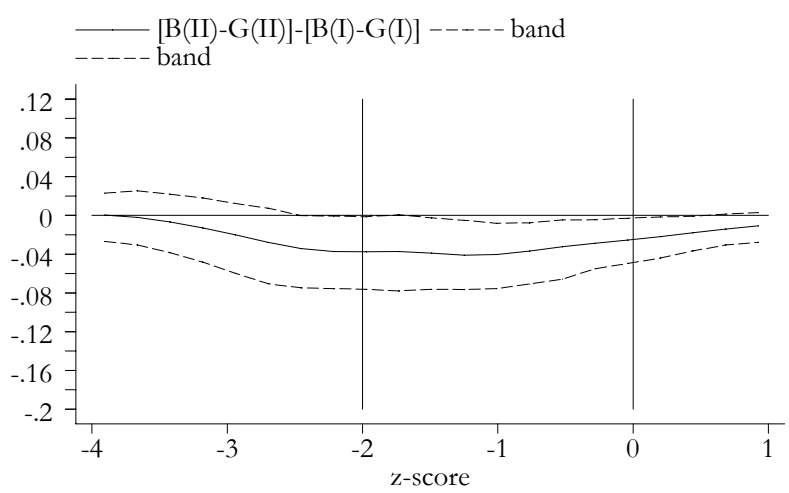

Height-for-age, Rural sector

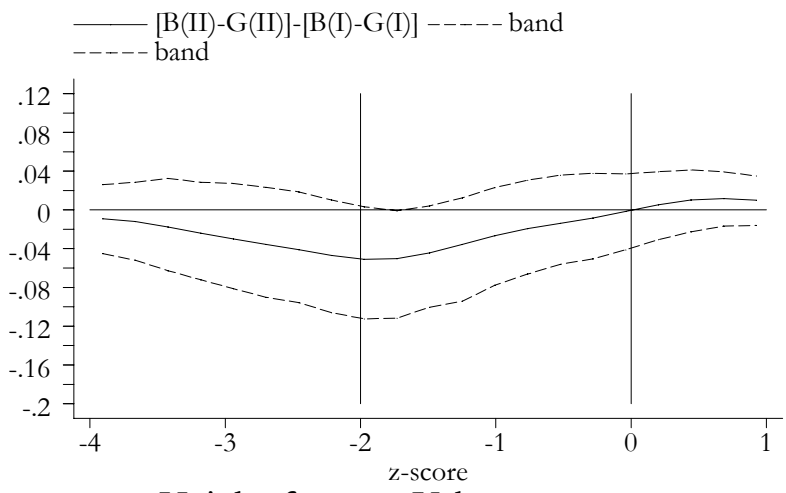

Height-for-age, Urban sector

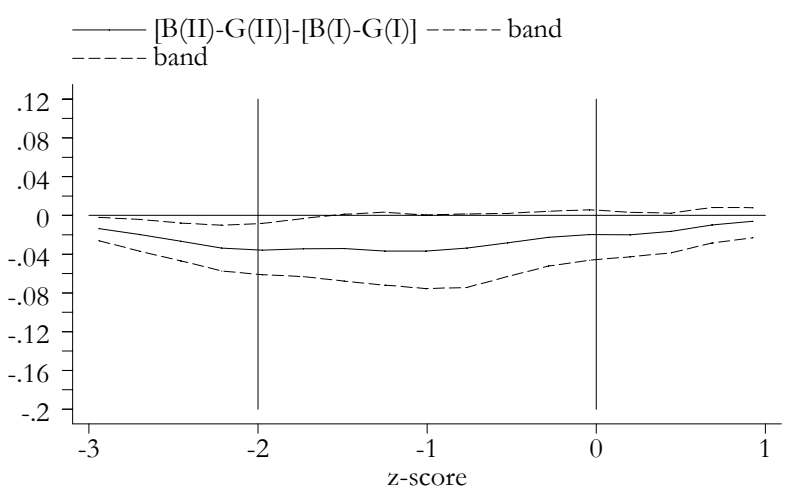

Weight-for-Height, Rural sector

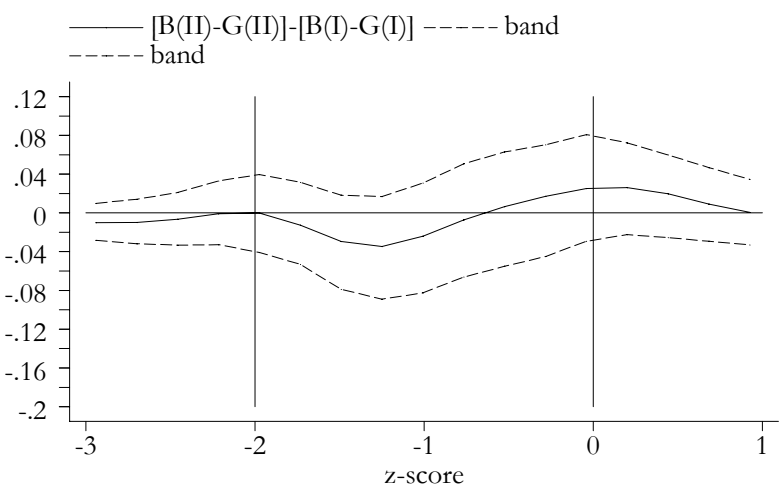

Weight-for-Height, Urban sector

Figure 8: Change over time of gender differences in nutritional status. North India (Gujarat, Haryana, Jammu, Punjab, Rajasthan, Uttar Pradesh, and New Delhi), excluding Phase I states. Each continuous line represents the change over time of the pointwise gender difference in distributions. The dashed lines represent $95 \%$ confidence bands (see text for details). 


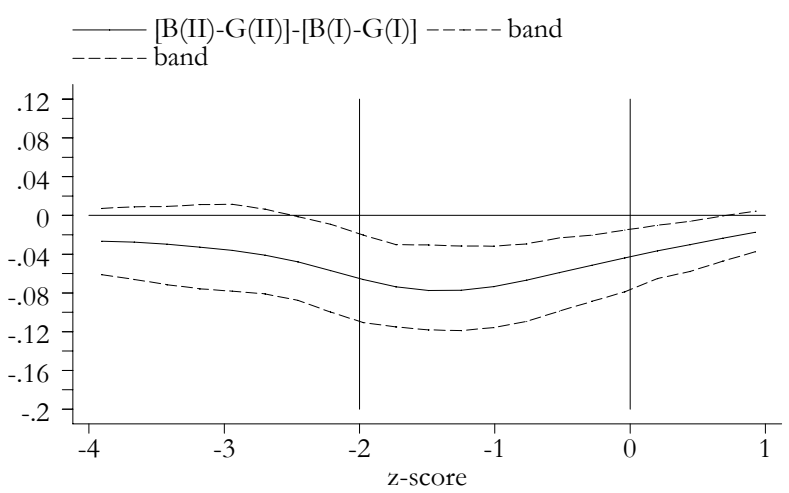

Height-for-age, Rural sector

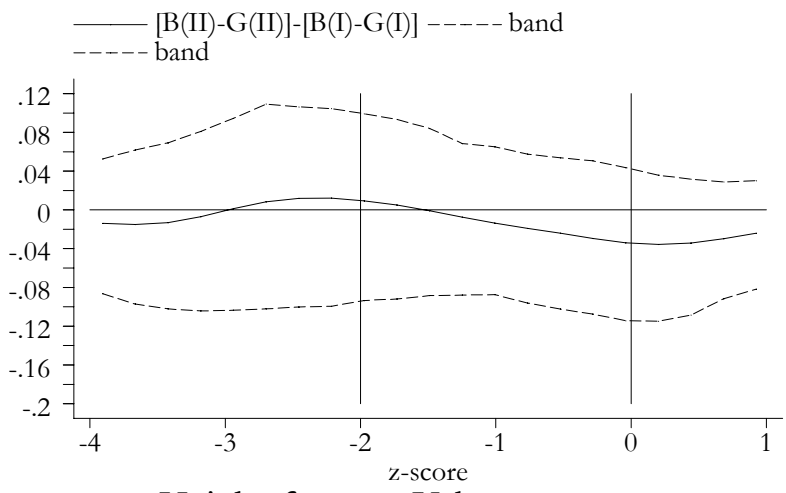

Height-for-age, Urban sector

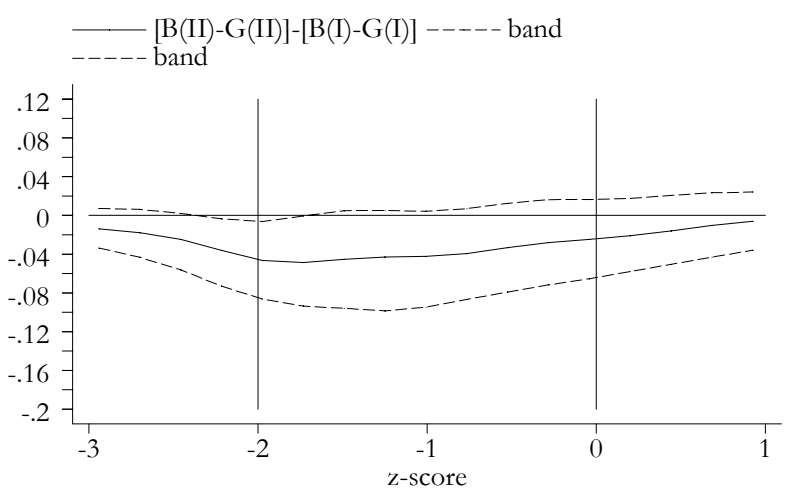

Weight-for-Height, Rural sector

[B(II)-G(II)]-[B(I)-G(I)] - - - - band

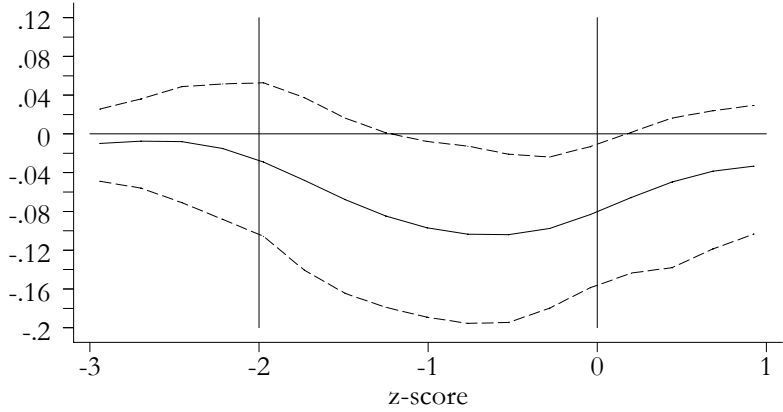

Weight-for-Height, Urban sector

Figure 9: Change over time of gender differences in nutritional status. East India (Assam, Bihar, Orissa), excluding Phase I states. Each continuous line represents the change over time of the pointwise gender difference in distributions. The dashed lines represent $95 \%$ confidence bands (see text for details). 


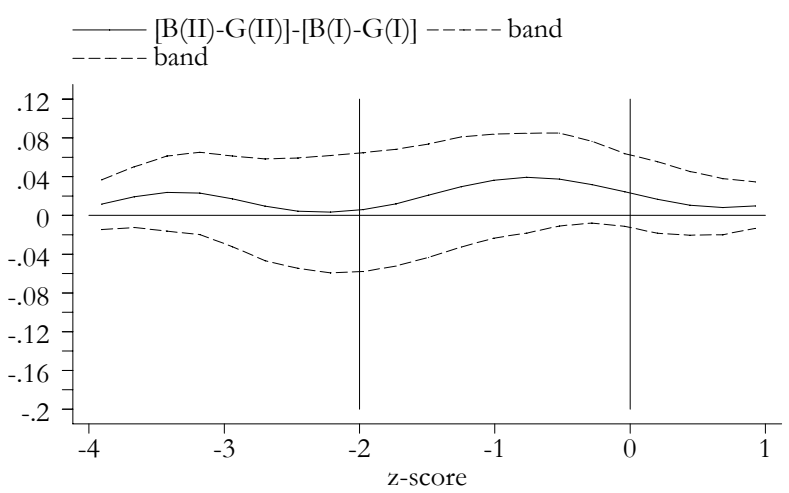

Height-for-age, Rural sector

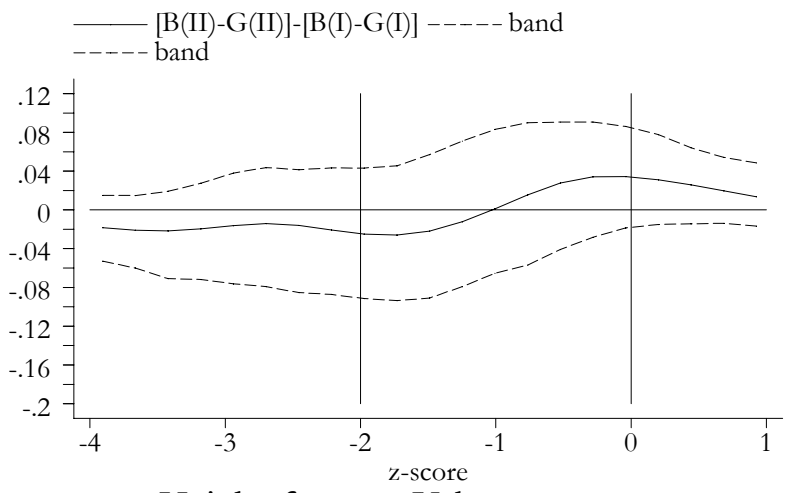

Height-for-age, Urban sector

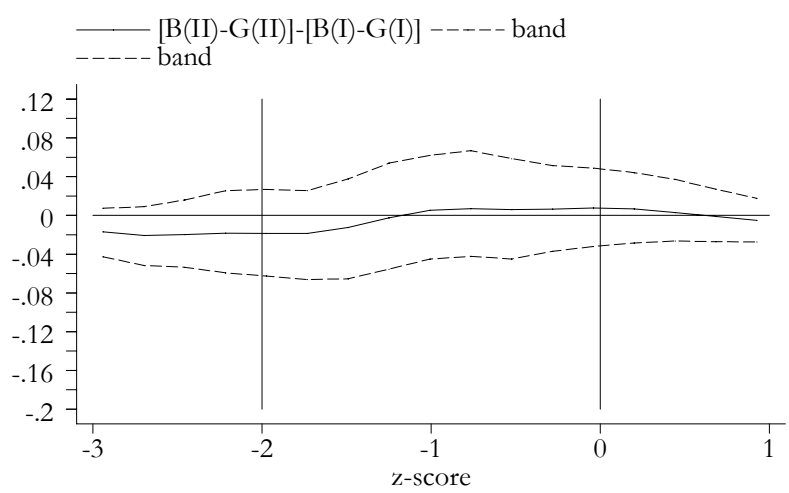

Weight-for-Height, Rural sector

[B(II)-G(II)]-[B(I)-G(I)] --.-- band

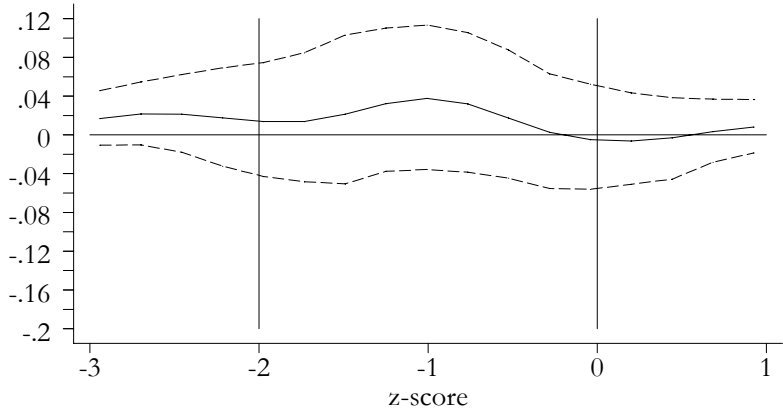

Weight-for-Height, Urban sector

Figure 10: Change over time of gender differences in nutritional status. South India (Kerala, Karnataka, and Maharashtra), excluding Phase I states. Each continuous line represents the change over time of the pointwise gender difference in distributions. The dashed lines represent $95 \%$ confidence bands (see text for details). 

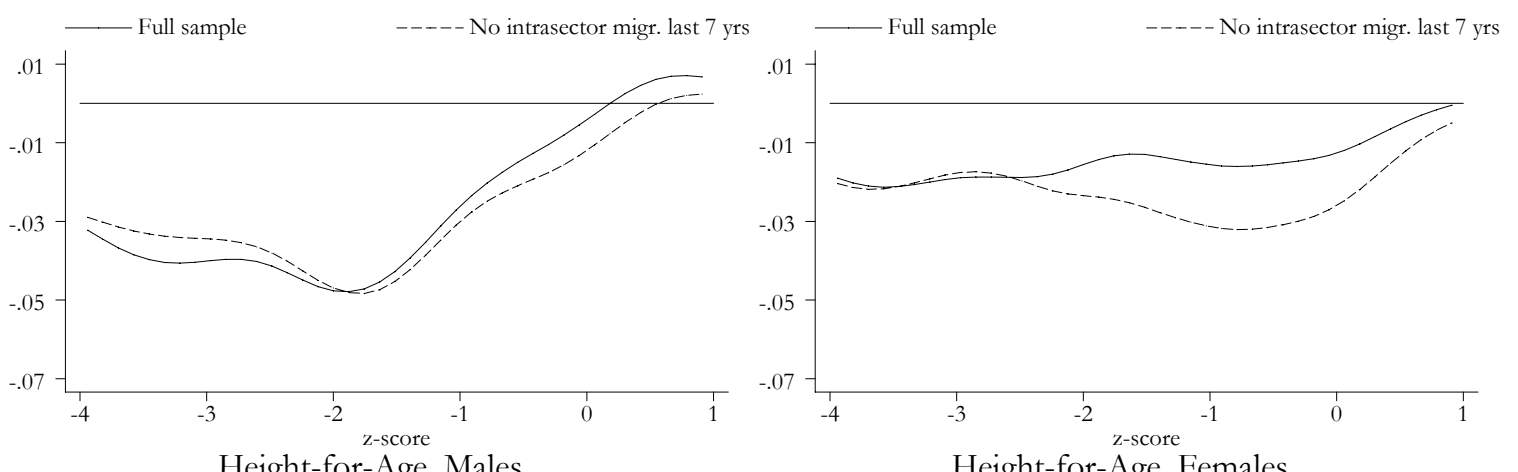

Height-for-Age, Males

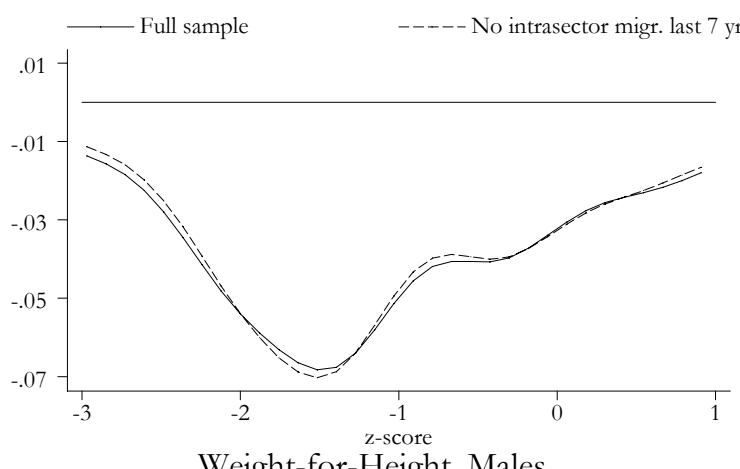

Height-for-Age, Females

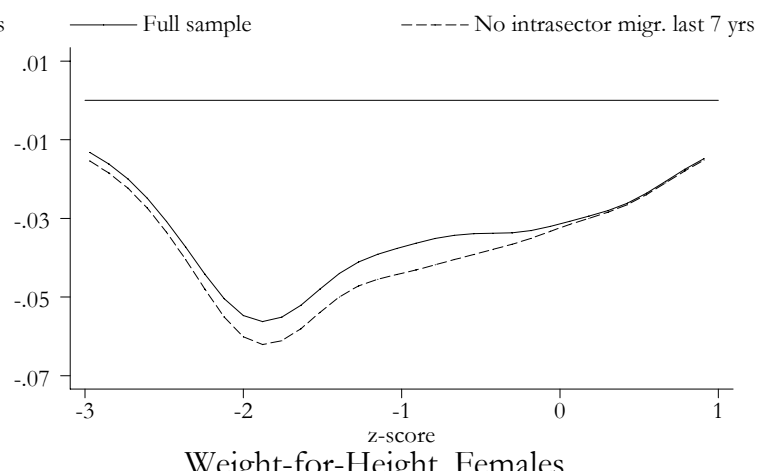

Weight-for-Height, Males

Weight-for-Height, Females

Figure 11: All India, Urban, excluding states with no height in NFHS-I
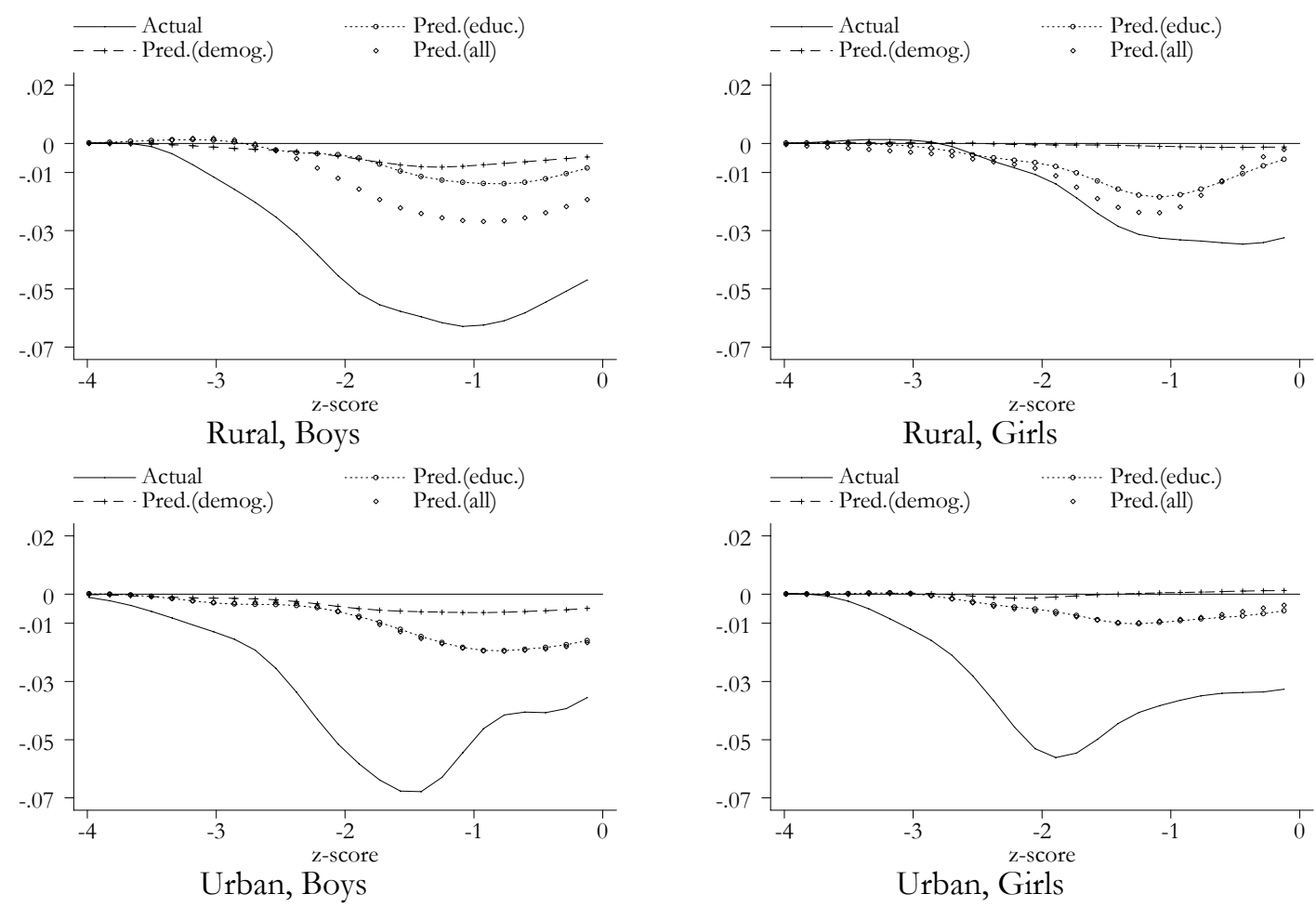

Figure 12: Counterfactual Distributions, Weight-for-Height. 

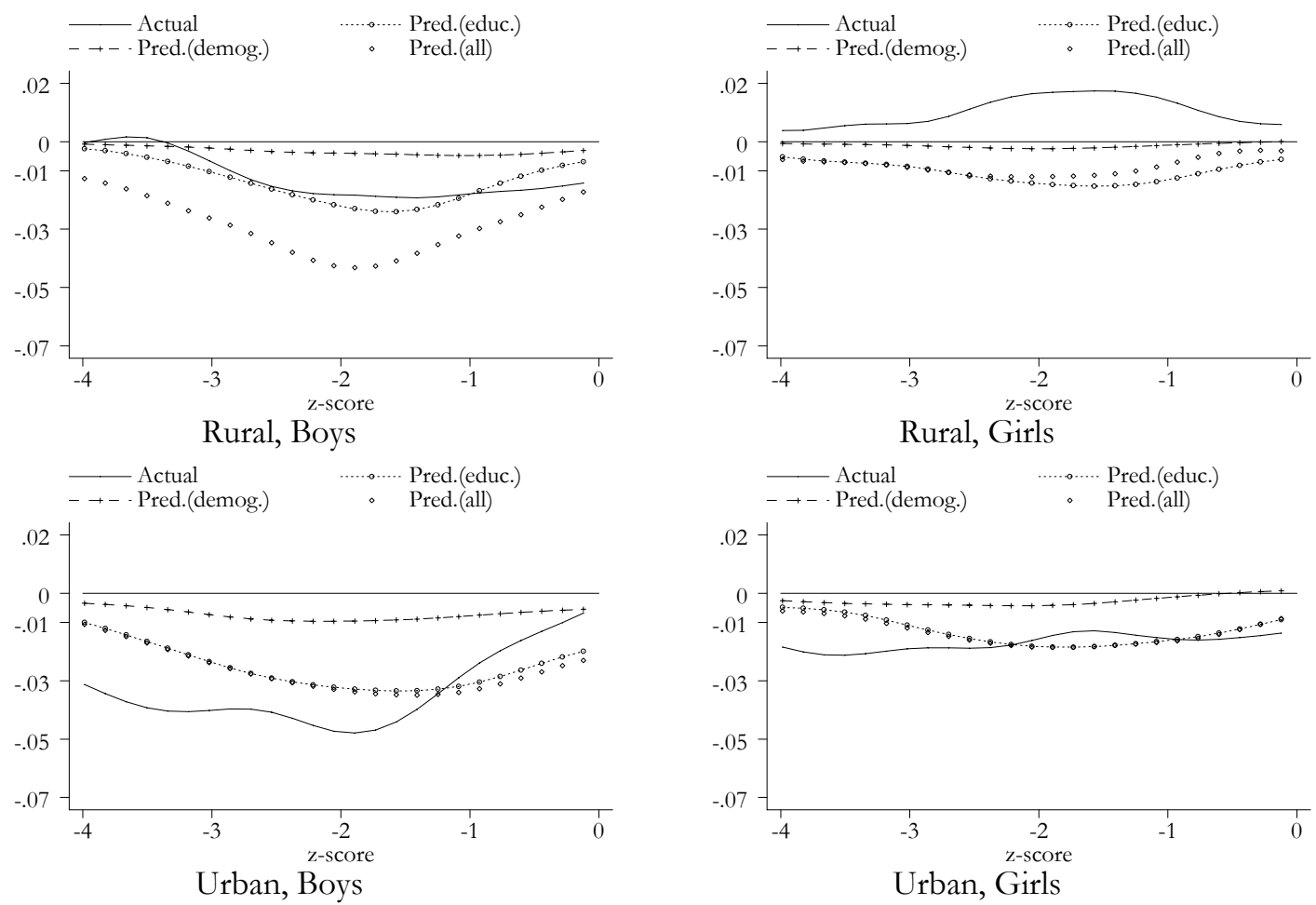

Figure 13: Counterfactual Distributions, Height-for-age. 
Table 1: Summary Statistics: Women

\begin{tabular}{|c|c|c|c|c|}
\hline \multirow{3}{*}{$\begin{array}{l}\text { No. of households } \\
\text { No. of ever married women age } 15-49 \\
\text { No. of ever married age } 13-14 \\
\% \text { living in rural areas (weighted) }\end{array}$} & \multicolumn{2}{|c|}{ NFHS-I (1992-93) } & \multicolumn{2}{|c|}{ NFHS-II (1998-99) } \\
\hline & & & & \\
\hline & Urban & Rural & Urban & Rural \\
\hline $\begin{array}{l}\text { No. of children age } 0-35 \text { months } \\
\text { No. of children age } 36-47 \text { months }\end{array}$ & $\begin{array}{l}9,357 \\
3,080\end{array}$ & $\begin{array}{c}24,826 \\
8,012\end{array}$ & $\begin{array}{c}7,609 \\
0\end{array}$ & $\begin{array}{c}21,053 \\
0\end{array}$ \\
\hline Means (weighted) & & & & \\
\hline Age at first marriage & 17.9 & 16.2 & 18.2 & 16.4 \\
\hline Household size & 6.73 & 7.24 & 6.48 & 6.93 \\
\hline No. children below age 5 & 0.91 & 1.14 & 0.81 & 1.03 \\
\hline Not using any contraceptive & 51.9 & 65.0 & 45.5 & 58.1 \\
\hline Contraceptive: Female sterilization & 28.6 & 24.9 & 33.7 & 31.4 \\
\hline Contraceptive: Pill & 1.8 & 0.9 & 2.5 & 1.8 \\
\hline Contraceptive: Condom & 5.5 & 1.2 & 6.8 & 1.5 \\
\hline$\%$ desiring 3 children or less* & 80.3 & 65.1 & 85.6 & 73.1 \\
\hline$\%$ desiring 2 children or less* & 56.6 & 34.4 & 67.4 & 46.0 \\
\hline
\end{tabular}

Source: Authors' calculations. *Calculated including only numeric answers (while excluding responses such as "up to God" etc.). All statistics are calculated including only women of age 15-49. 
Table 2: Summary Statistics: Women (continued)

\begin{tabular}{|c|c|c|c|c|}
\hline & \multicolumn{2}{|c|}{ NFHS-I (1992-93) } & \multicolumn{2}{|c|}{ NFHS-II (1998-99) } \\
\hline & Urban & Rural & Urban & Rural \\
\hline No. of children age $0-35$ months & 9,357 & 24,826 & 7,266 & 21,053 \\
\hline North & 4,117 & 10,870 & 3,371 & 9,510 \\
\hline East & 1,251 & 4,424 & 963 & 4,779 \\
\hline South & 1,797 & 3,969 & 2,209 & 3,351 \\
\hline Desired $\%$ of females* & 44.1 & 40.4 & 45.2 & 42.2 \\
\hline North & 41.9 & 38.0 & 43.3 & 39.4 \\
\hline East & 43.3 & 40.4 & 44.8 & 42.4 \\
\hline South & 46.3 & 43.5 & 47.2 & 45.6 \\
\hline \% Women Working & 21.1 & 37.3 & 24.0 & 42.0 \\
\hline North & 16.5 & 29.5 & 21.2 & 37.3 \\
\hline East & 16.2 & 26.7 & 16.3 & 27.4 \\
\hline South & 27.5 & 58.3 & 29.3 & 61.2 \\
\hline \% Women Working who receive earnings & 89.1 & 60.2 & 89.0 & 62.6 \\
\hline North & 88.5 & 43.0 & 87.2 & 43.9 \\
\hline East & 88.0 & 69.7 & 93.5 & 79.5 \\
\hline South & 89.8 & 68.6 & 89.5 & 70.4 \\
\hline \% Women with no education & 35.6 & 71.0 & 29.2 & 62.4 \\
\hline North & 42.1 & 78.4 & 33.9 & 70.5 \\
\hline East & 37.7 & 71.7 & 30.3 & 64.6 \\
\hline South & 28.5 & 59.8 & 24.1 & 50.0 \\
\hline \% Women complete secondary or above & 10.7 & 0.8 & 32.8 & 7.7 \\
\hline North & 12.1 & 0.7 & 34.9 & 6.1 \\
\hline East & 11.4 & 0.7 & 29.1 & 5.7 \\
\hline South & 9.1 & 1.2 & 31.9 & 11.4 \\
\hline$\%$ Partners with no education & 17.1 & 40.5 & 13.5 & 34.1 \\
\hline North & 18.4 & 39.9 & 14.0 & 32.0 \\
\hline East & 19.9 & 43.5 & 15.2 & 38.9 \\
\hline South & 14.7 & 38.7 & 12.4 & 32.4 \\
\hline$\%$ Partners with complete secondary or above & 27.0 & 8.5 & 50.0 & 23.2 \\
\hline North & 28.9 & 10.2 & 53.9 & 27.0 \\
\hline East & 30.1 & 8.1 & 47.5 & 19.5 \\
\hline South & 24.0 & 6.5 & 47.1 & 22.0 \\
\hline
\end{tabular}

Source: Authors' calculations. Statistics reported to the right of the variable description refer to all India. *Calculated including only numeric answers (while excluding responses such as "up to God" etc.). All statistics are calculated including only women of age 15-49. 
Table 3: Tests of Equality and Stochastic Dominance: Changes Over Time, All India

\begin{tabular}{|c|c|c|c|c|c|c|}
\hline & \multicolumn{3}{|c|}{ Rural } & \multicolumn{3}{|c|}{ Urban } \\
\hline & \multicolumn{2}{|c|}{ p-value } & \multirow[b]{2}{*}{$\begin{array}{c}\text { No FOSD } \\
(3) \\
\end{array}$} & \multicolumn{2}{|c|}{$\mathrm{p}$-value } & \multirow[b]{2}{*}{$\begin{array}{c}\text { No FOSD } \\
(6)\end{array}$} \\
\hline & $\begin{array}{c}\text { Equality } \\
(1)\end{array}$ & $\begin{array}{c}\text { FOSD } \\
(2) \\
\end{array}$ & & $\begin{array}{c}\text { Equality } \\
(4)\end{array}$ & $\begin{array}{c}\text { FOSD } \\
(5) \\
\end{array}$ & \\
\hline Weight-for-height & 0 & 1 & $\begin{array}{l}{\left[\begin{array}{ll}-3 & 1\end{array}\right]} \\
{\left[\begin{array}{ll}-3 & 1\end{array}\right]} \\
\text { NOSD }\end{array}$ & 0 & 1 & $\begin{array}{c}{\left[\begin{array}{ll}-3 & 1\end{array}\right]} \\
{\left[\begin{array}{ll}-3 & 1\end{array}\right]} \\
{\left[\begin{array}{ll}-3 & -.96\end{array}\right]}\end{array}$ \\
\hline Height-for-age & .828 & .464 & $\begin{array}{l}\text { NOSD } \\
\text { NOSD } \\
\text { NOSD }\end{array}$ & .06 & .764 & $\begin{array}{l}{\left[\begin{array}{ll}-4 & -1.55\end{array}\right]} \\
{\left[\begin{array}{ll}-4 & -3.02\end{array}\right]} \\
{\left[\begin{array}{ll}-4 & -3.27\end{array}\right]}\end{array}$ \\
\hline Weight-for-age & 0 & .828 & $\begin{array}{c}{\left[\begin{array}{ll}-4 & .41\end{array}\right]} \\
{\left[\begin{array}{cc}-4 & -3.39\end{array}\right]} \\
\text { NOSD }\end{array}$ & .004 & 1 & $\begin{array}{c}{\left[\begin{array}{ll}-4 & 2\end{array}\right]} \\
{\left[\begin{array}{ll}-4 & 1.88\end{array}\right]} \\
{\left[\begin{array}{ll}-4 & .78\end{array}\right]}\end{array}$ \\
\hline $\begin{array}{l}\text { Notes: Authors' calcul } \\
\text { report p-values of Kolı } \\
\text { distribution in 1998-99 } \\
\text { report the results of ar } \\
\text { and } 1 \text { percent significa } \\
\text { correlation. }\end{array}$ & $\begin{array}{l}\text { tions from } 1 \\
\text { ogorov-Smi } \\
\text { (weakly) fir } \\
\text { intersection } \\
\text { ce level. See }\end{array}$ & $\begin{array}{l}\text {-I and N } \\
\text { tests of } \\
\text { ler stoch } \\
\text { n test of } \\
\text { for deta }\end{array}$ & $\begin{array}{l}\text { II, for all Inc } \\
\text { y of distribu } \\
\text { ly dominates } \\
\text { ull of no sto } \\
\text { the tests. Al }\end{array}$ & $\begin{array}{l}\text { cluding } \mathrm{P} \\
\text { In colum } \\
\text { distributio } \\
\text { c dominan } \\
\text { are robus }\end{array}$ & $\begin{array}{l}\text { states. } \\
\text { and } 5 \text { th } \\
992-93 . \\
\text { ing (top } \\
\text { he presel }\end{array}$ & $\begin{array}{l}\text { Imns } 1 \text { and } 4 \\
\text { il is that the } \\
\text { imns } 3 \text { and } 6 \\
\text { ottom) } 10,5 \\
\text { intracluster }\end{array}$ \\
\hline
\end{tabular}


Table 4: Tests of Equality and Stochastic Dominance: Changes Over Time, All India, By Gender

\begin{tabular}{|c|c|c|c|c|c|}
\hline \multicolumn{3}{|c|}{ Rural } & \multicolumn{3}{|c|}{ Urban } \\
\hline $\mathrm{p}-\mathrm{r}$ & & & $\mathrm{p}-\bar{\tau}$ & & \\
\hline $\begin{array}{c}\text { Equality } \\
\text { (1) }\end{array}$ & $\begin{array}{c}\text { FOSD } \\
(2)\end{array}$ & $\begin{array}{c}\text { No FOSD } \\
(3)\end{array}$ & $\begin{array}{c}\text { Equality } \\
\text { (4) }\end{array}$ & $\begin{array}{c}\text { FOSD } \\
(5)\end{array}$ & $\begin{array}{c}\text { No FOSD } \\
(6)\end{array}$ \\
\hline
\end{tabular}

\begin{tabular}{|c|c|c|c|c|c|c|}
\hline \multirow{4}{*}{ Height-for-age } & \multicolumn{6}{|c|}{ Males } \\
\hline & .195 & .575 & NOSD & .015 & .72 & {$\left[\begin{array}{ll}-4 & -1.45\end{array}\right]$} \\
\hline & & & NOSD & & & {$\left[\begin{array}{ll}-4 & -1.45\end{array}\right]$} \\
\hline & & & NOSD & & & {$\left[\begin{array}{ll}-4 & -3.08\end{array}\right]$} \\
\hline \multirow[t]{4}{*}{ Weight-for-height } & 0 & 1 & {$\left[\begin{array}{ll}-3 & 1\end{array}\right]$} & 0 & 1 & {$\left[\begin{array}{ll}-3 & -.88\end{array}\right]$} \\
\hline & & & {$\left[\begin{array}{ll}-3 & 1\end{array}\right]$} & & & {$\left[\begin{array}{ll}-3 & -.96\end{array}\right]$} \\
\hline & & & {$\left[\begin{array}{ll}-3 & 1\end{array}\right]$} & & & NOSD \\
\hline & \multicolumn{6}{|c|}{ Females } \\
\hline \multirow[t]{3}{*}{ Height-for-age } & .245 & .125 & NOSD & .50 & .965 & NOSD \\
\hline & & & NOSD & & & NOSD \\
\hline & & & NOSD & & & NOSD \\
\hline \multirow[t]{3}{*}{ Weight-for-height } & 0 & .92 & NOSD & .005 & 1 & {$\left[\begin{array}{ll}-3 & -1.20\end{array}\right]$} \\
\hline & & & NOSD & & & NOSD \\
\hline & & & NOSD & & & NOSD \\
\hline
\end{tabular}

Notes: Authors' calculations from NFHS-I and NFHS-II, for all India excluding Phase I states. Columns 1 and 4 report p-values of Kolmogorov-Smirnov tests of equality of distributions. In columns 2 and 5 the null is that the distribution in 1998-99 (weakly) first order stochastically dominates the distribution in 1992-93. Columns 3 and 6 report the results of an intersection-union test of the null of no stochastic dominance, using (top to bottom) 10,5 and 1 percent significance level. See text for details on the tests. All tests are robust to the presence of intracluster correlation. 


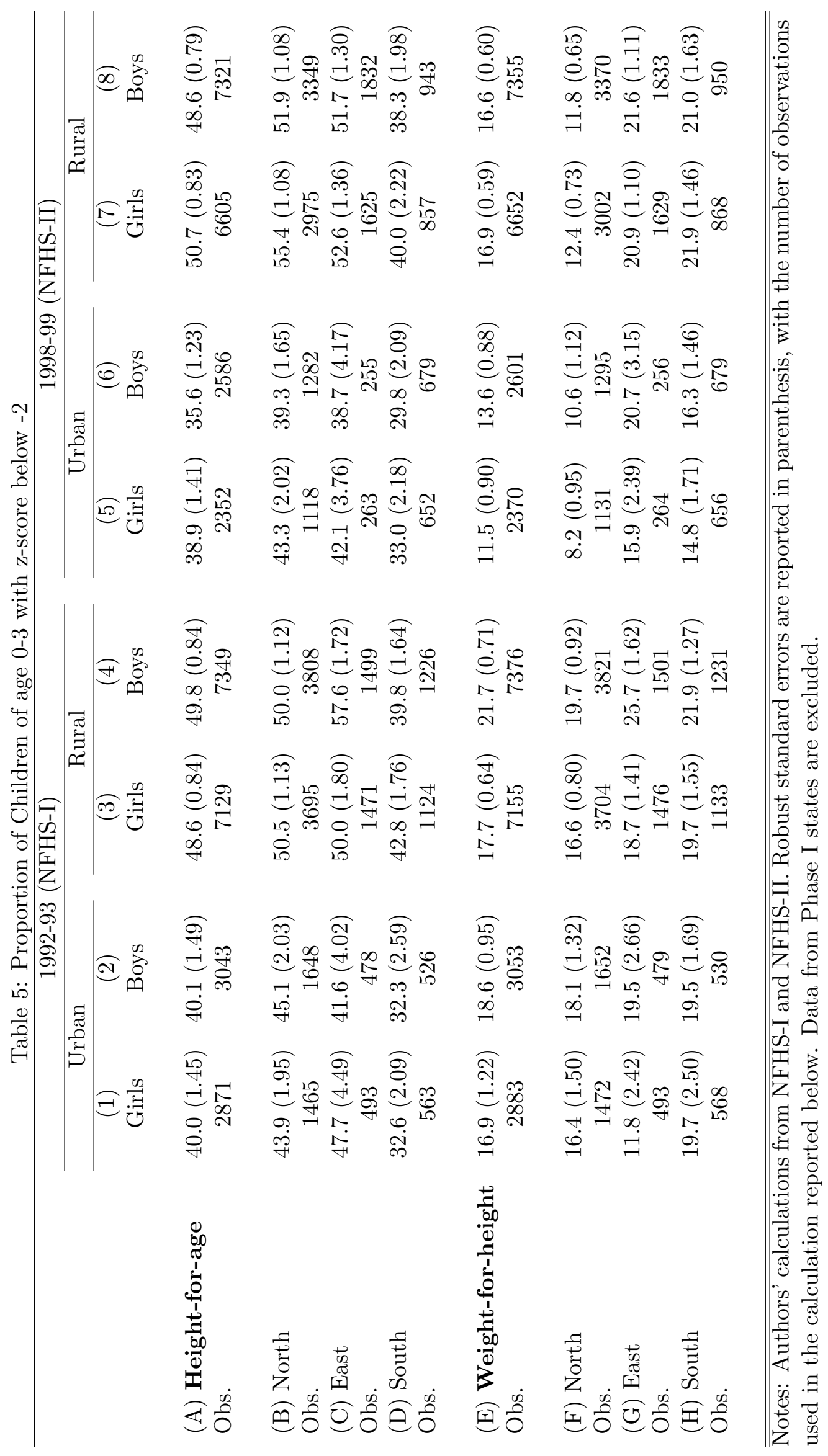


Table 6: Tests of Equality and Stochastic Dominance - Changes over time, by Region

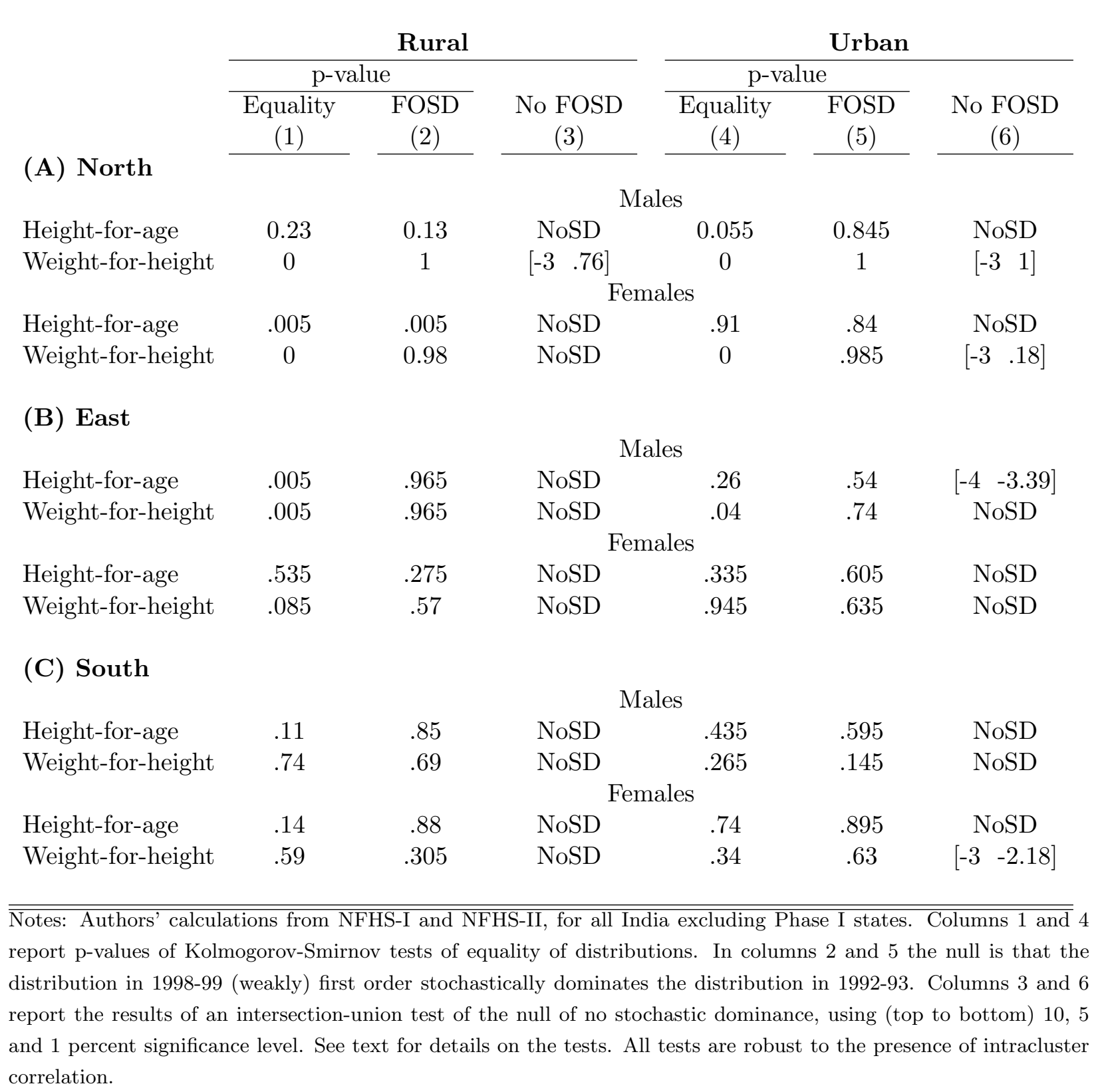




\begin{tabular}{|c|c|c|c|}
\hline & \multicolumn{2}{|c|}{ Gender } & \multirow[b]{2}{*}{ Total } \\
\hline & Male & Female & \\
\hline & \multicolumn{2}{|c|}{ Urban } & \\
\hline$\%$ moved in 6 years before survey & 0.52 & 0.53 & 0.52 \\
\hline \multirow[t]{2}{*}{$\%$ moved and changed sector in 6 years before survey } & 0.24 & 0.25 & 0.25 \\
\hline & \multicolumn{2}{|c|}{ Rural } & \\
\hline$\%$ moved in 6 years before survey & 0.41 & 0.41 & 0.41 \\
\hline$\%$ moved and changed sector in 6 years before survey & 0.05 & 0.05 & 0.05 \\
\hline
\end{tabular}

NFHS-II (1998-99), All India. Figures refer to the proportion of mothers of children of age 0-3 who moved to their current residence during the six years before the survey. 


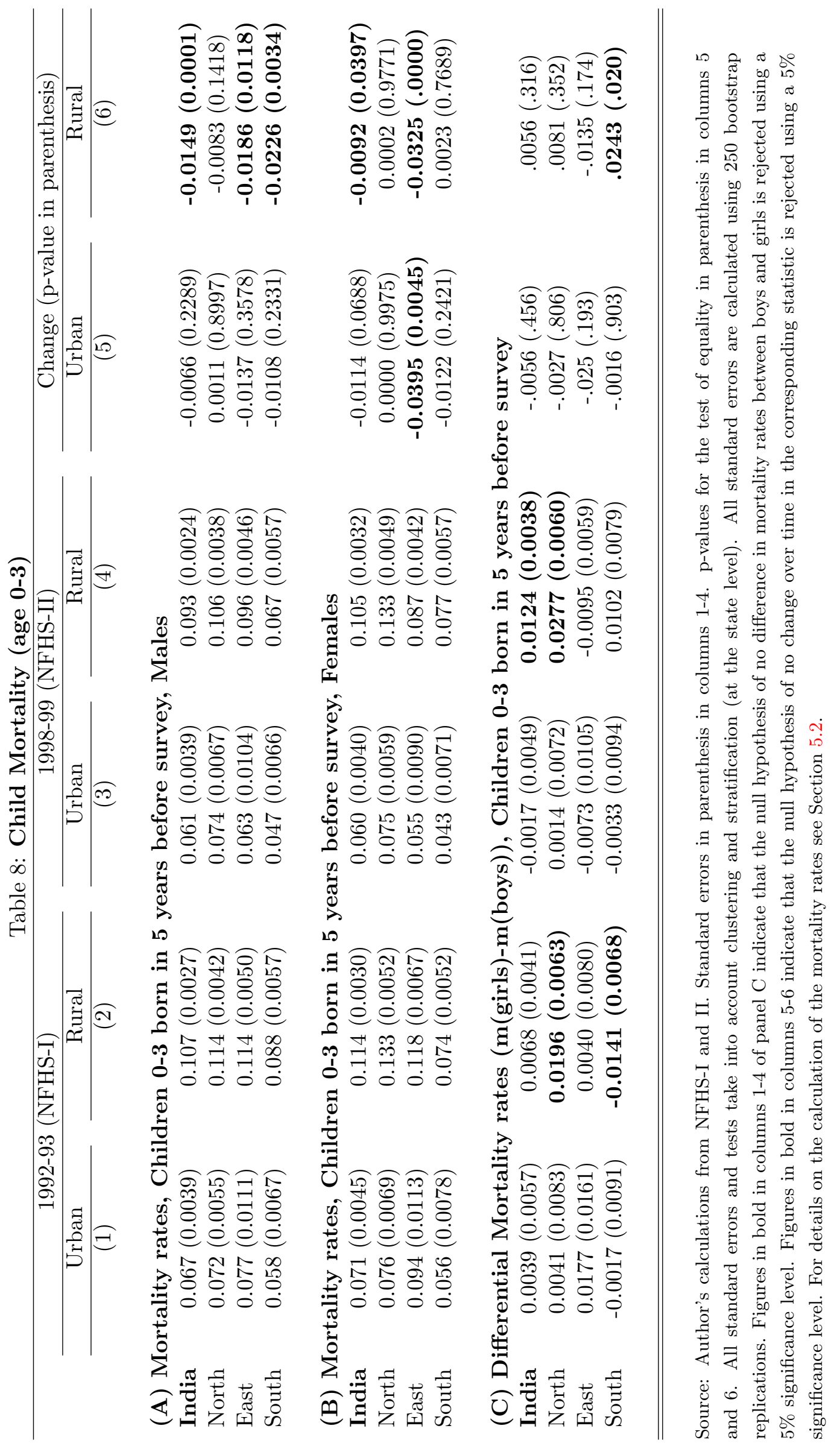


Table 9: Oaxaca Decomposition, Weight-for-Height, Rural North-East

\begin{tabular}{|c|c|c|c|c|c|c|c|}
\hline Males & $\beta_{92-93}$ & $t_{92-93}$ & $\beta_{98-99}$ & $t_{98-99}$ & & $\Delta_{X}$ & $\Delta_{\beta}$ \\
\hline Mother literate below middle sch. & -0.0452 & -2.05 & -0.0059 & -0.34 & & -0.0009 & 0.0055 \\
\hline Mother completed middle sch. & 0.0091 & 0.26 & -0.0198 & -0.94 & & 0.0003 & -0.0022 \\
\hline Mother completed at least high school & -0.0331 & -0.9 & -0.0108 & -0.5 & & -0.0009 & 0.0018 \\
\hline Father has primary education & 0.0229 & 1.09 & -0.0048 & -0.27 & & -0.0011 & -0.0042 \\
\hline Father has secondary education & -0.0242 & -1.28 & -0.0212 & -1.43 & & -0.0004 & 0.0011 \\
\hline Father has higher education & 0.0778 & 2.07 & -0.0146 & -0.74 & & 0.0073 & -0.0141 \\
\hline High birth order (above 3) & 0.0006 & 0.04 & 0.0004 & 0.03 & & 0.0000 & -0.0001 \\
\hline Household head is woman & -0.0463 & -1.49 & -0.0184 & -0.79 & & -0.0002 & 0.0014 \\
\hline Muslim & -0.0009 & -0.04 & 0.0031 & 0.14 & & 0.0000 & 0.0005 \\
\hline Other religions & -0.0059 & -0.24 & -0.0471 & -2.22 & & 0.0001 & -0.0017 \\
\hline Health sub-centre in village & 0.0237 & 1.17 & -0.0169 & -1.27 & & 0.0015 & -0.0134 \\
\hline Primary Health Center in village & -0.0321 & -1.29 & -0.0207 & -1.16 & & -0.0012 & 0.0013 \\
\hline Village has no drainage & 0.0163 & 0.87 & -0.0068 & -0.54 & & -0.0006 & -0.0130 \\
\hline Anganwadi in village & -0.0554 & -2.91 & 0.0117 & 0.86 & & -0.0103 & 0.0361 \\
\hline Mahila Mandal in village & 0.0114 & 0.47 & -0.0017 & -0.11 & & -0.0007 & -0.0026 \\
\hline Pharmacy in village & 0.0221 & 1.03 & -0.0044 & -0.26 & & -0.0014 & -0.0056 \\
\hline Fair Price Shop (PDS) in village & -0.0207 & -1 & -0.0150 & -1.1 & & -0.0039 & 0.0031 \\
\hline Village is electrified & 0.0188 & 0.89 & -0.0444 & -2.66 & & 0.0010 & -0.0456 \\
\hline \multirow[t]{2}{*}{ Household owns land } & -0.0081 & -0.46 & -0.0165 & -1.26 & & 0.0004 & -0.0056 \\
\hline & & & & & Total Changes & -0.0161 & -0.0461 \\
\hline Obs. & \multicolumn{2}{|c|}{4389} & \multicolumn{2}{|c|}{4885} & M. Educ. & -0.0015 & 0.0051 \\
\hline$R^{2}$ & \multicolumn{2}{|c|}{0.0428} & \multicolumn{2}{|c|}{0.0251} & F. Educ & 0.0057 & -0.0173 \\
\hline$\hat{P}(z<-2)$ & \multicolumn{2}{|c|}{0.2156} & \multicolumn{2}{|c|}{0.1539} & Health Amen. & -0.0127 & 0.0027 \\
\hline Females & $\beta_{92-93}$ & $t_{92-93}$ & $\beta_{98-99}$ & $t_{98-99}$ & & $\Delta_{X}$ & $\Delta_{\beta}$ \\
\hline Mother literate below middle sch. & -0.0279 & -1.38 & 0.0220 & 1.19 & & -0.0004 & 0.0070 \\
\hline Mother completed middle sch. & -0.1179 & -5.05 & -0.0224 & -0.90 & & -0.0013 & 0.0054 \\
\hline Mother completed at least high school & -0.0785 & -2.55 & -0.0051 & -0.23 & & -0.0017 & 0.0056 \\
\hline Father has primary education & -0.0056 & -0.28 & -0.0437 & -2.25 & & 0.0002 & -0.0060 \\
\hline Father has secondary education & -0.0001 & -0.01 & -0.0352 & -2.20 & & 0.0000 & -0.0128 \\
\hline Father has higher education & 0.0255 & 0.75 & -0.0798 & -4.02 & & 0.0022 & -0.0153 \\
\hline High birth order (above 3 ) & 0.0033 & 0.22 & 0.0210 & 1.62 & & -0.0001 & 0.0062 \\
\hline Household head is woman & -0.0202 & -0.72 & -0.0083 & -0.30 & & -0.0001 & 0.0006 \\
\hline Muslim & 0.0102 & 0.46 & -0.0416 & -2.27 & & -0.0002 & -0.0067 \\
\hline Other religions & 0.0509 & 2.17 & -0.0477 & -1.94 & & -0.0008 & -0.0035 \\
\hline Health sub-centre in village & 0.0392 & 1.85 & -0.0050 & -0.36 & & 0.0034 & -0.0151 \\
\hline Primary Health Center in village & -0.0086 & -0.22 & 0.0110 & 0.51 & & -0.0003 & 0.0023 \\
\hline Village has no drainage & 0.0072 & 0.40 & -0.0114 & -0.87 & & -0.0003 & -0.0103 \\
\hline Anganwadi in village & -0.0176 & -0.98 & 0.0093 & 0.69 & & -0.0032 & 0.0142 \\
\hline Mahila Mandal in village & -0.0121 & -0.65 & -0.0193 & -1.24 & & 0.0008 & -0.0014 \\
\hline Pharmacy in village & -0.0181 & -0.92 & -0.0009 & -0.05 & & 0.0009 & 0.0038 \\
\hline Fair Price Shop (PDS) in village & -0.0013 & -0.08 & -0.0009 & -0.07 & & -0.0003 & 0.0002 \\
\hline Village is electrified & 0.0035 & 0.19 & -0.0666 & -3.93 & & 0.0002 & -0.0513 \\
\hline \multirow[t]{2}{*}{ Household owns land } & -0.0098 & -0.62 & 0.0030 & 0.22 & & 0.0003 & 0.0086 \\
\hline & \multicolumn{2}{|c|}{4280} & \multirow{2}{*}{\multicolumn{2}{|c|}{4340}} & Total Changes & -0.0029 & -0.0110 \\
\hline Obs. & \multirow{2}{*}{\multicolumn{2}{|c|}{$\begin{array}{c}4289 \\
0.0335\end{array}$}} & & & M. Educ. & -0.0034 & 0.0179 \\
\hline$R^{2}$ & & & \multicolumn{2}{|c|}{0.0284} & F. Educ & 0.0024 & -0.0341 \\
\hline$\hat{P}(z<-2)$ & \multicolumn{2}{|c|}{0.1678} & \multicolumn{2}{|c|}{0.1539} & Health Amen. & 0.0013 & -0.0065 \\
\hline
\end{tabular}


Table 10: Oaxaca Decomposition, Weight-for-Height, Rural South

\begin{tabular}{|c|c|c|c|c|c|c|c|}
\hline Males & $\beta_{92-93}$ & $t_{92-93}$ & $\beta_{98-99}$ & $t_{98-99}$ & & $\Delta_{X}$ & $\Delta_{\beta}$ \\
\hline Mother literate below middle sch. & 0.0079 & 0.22 & -0.0159 & -0.35 & & -0.0007 & -0.0046 \\
\hline Mother completed middle sch. & -0.0160 & -0.28 & -0.0700 & -1.26 & & -0.0007 & -0.0078 \\
\hline Mother completed at least high school & -0.0570 & -1.21 & -0.0225 & -0.43 & & -0.0067 & 0.0076 \\
\hline Father has primary education & -0.0405 & -1.07 & -0.0088 & -0.15 & & 0.0078 & 0.0052 \\
\hline Father has secondary education & -0.0217 & -0.54 & -0.1171 & -2.58 & & -0.0018 & -0.0389 \\
\hline Father has higher education & -0.0252 & -0.34 & -0.0870 & -1.41 & & -0.0039 & -0.0120 \\
\hline High birth order (above 3) & 0.0386 & 1.24 & 0.0129 & 0.29 & & -0.0021 & -0.0047 \\
\hline Household head is woman & -0.0103 & -0.26 & -0.0040 & -0.08 & & 0.0003 & 0.0005 \\
\hline Muslim & -0.0130 & -0.34 & -0.0421 & -0.93 & & 0.0000 & -0.0044 \\
\hline Other religions & -0.0308 & -0.60 & -0.1003 & -1.64 & & 0.0006 & -0.0037 \\
\hline Health sub-centre in village & -0.0317 & -0.88 & 0.0404 & 1.22 & & 0.0017 & 0.0353 \\
\hline Primary Health Center in village & -0.0784 & -2.13 & 0.0320 & 0.60 & & -0.0073 & 0.0352 \\
\hline Village has no drainage & -0.0721 & -2.77 & 0.0459 & 1.32 & & -0.0001 & 0.0453 \\
\hline Anganwadi in village & 0.0215 & 0.75 & 0.0564 & 1.40 & & 0.0043 & 0.0314 \\
\hline Mahila Mandal in village & 0.0023 & 0.08 & -0.0335 & -1.01 & & 0.0001 & -0.0239 \\
\hline Pharmacy in village & 0.0727 & 1.94 & -0.0368 & -0.69 & & -0.0001 & -0.0384 \\
\hline Fair Price Shop (PDS) in village & -0.1039 & -3.09 & -0.0488 & -1.15 & & 0.0064 & 0.0401 \\
\hline Village is electrified & 0.0241 & 0.29 & -0.0599 & -0.49 & & -0.0007 & -0.0805 \\
\hline \multirow[t]{2}{*}{ Household owns land } & -0.0229 & -0.74 & -0.0378 & -1.15 & & 0.0011 & -0.0092 \\
\hline & & & & Total Changes & -0.0017 & -0.0143 \\
\hline Obs. & \multicolumn{2}{|c|}{1152} & \multirow{2}{*}{\multicolumn{2}{|c|}{$\begin{array}{c}878 \\
0.087\end{array}$}} & M. Educ. & -0.0081 & -0.0048 \\
\hline$R^{2}$ & \multicolumn{2}{|c|}{0.0596} & & & F. Educ & 0.0021 & -0.0457 \\
\hline$\hat{P}(z<-2)$ & \multicolumn{2}{|c|}{0.2214} & \multicolumn{2}{|c|}{0.2057} & Health Amen. & -0.0013 & 0.0849 \\
\hline Females & $\beta_{92-93}$ & $\mathrm{t}_{92-93}$ & $\beta_{98-99}$ & $t_{98-99}$ & & $\Delta_{X}$ & $\Delta_{\beta}$ \\
\hline Mother literate below middle sch. & -0.0723 & -2.10 & 0.0264 & 0.58 & & -0.0010 & 0.0240 \\
\hline Mother completed middle sch. & -0.1046 & -2.28 & -0.0026 & -0.05 & & -0.0028 & 0.0139 \\
\hline Mother completed at least high school & -0.1234 & -2.67 & -0.0161 & -0.32 & & -0.0118 & 0.0215 \\
\hline Father has primary education & -0.0616 & -1.68 & -0.0295 & -0.51 & & 0.0090 & 0.0053 \\
\hline Father has secondary education & -0.0437 & -1.06 & -0.0449 & -0.92 & & -0.0031 & -0.0005 \\
\hline Father has higher education & -0.0344 & -0.54 & -0.1126 & -1.97 & & -0.0045 & -0.0139 \\
\hline High birth order (above 3 ) & -0.0101 & -0.27 & 0.1648 & 3.29 & & 0.0005 & 0.0303 \\
\hline Household head is woman & -0.0245 & -0.64 & 0.0181 & 0.36 & & 0.0005 & 0.0034 \\
\hline Muslim & -0.0389 & -1.11 & -0.0897 & -2.39 & & -0.0006 & -0.0075 \\
\hline Other religions & 0.0173 & 0.35 & -0.1501 & -3.95 & & -0.0004 & -0.0098 \\
\hline Health sub-centre in village & -0.0446 & -1.15 & -0.0002 & -0.01 & & 0.0030 & 0.0208 \\
\hline Primary Health Center in village & -0.0672 & -1.43 & 0.0026 & 0.06 & & -0.0060 & 0.0212 \\
\hline Village has no drainage & 0.0184 & 0.56 & 0.0433 & 1.51 & & 0.0008 & 0.0106 \\
\hline Anganwadi in village & 0.0314 & 0.90 & 0.0447 & 1.06 & & 0.0053 & 0.0119 \\
\hline Mahila Mandal in village & -0.0155 & -0.46 & 0.0112 & 0.36 & & -0.0007 & 0.0180 \\
\hline Pharmacy in village & 0.1280 & 2.48 & -0.0526 & -1.34 & & 0.0038 & -0.0659 \\
\hline Fair Price Shop (PDS) in village & -0.0224 & -0.54 & -0.0197 & -0.50 & & 0.0009 & 0.0021 \\
\hline Village is electrified & -0.0673 & -0.42 & -0.0082 & -0.08 & & 0.0016 & 0.0570 \\
\hline \multirow[t]{2}{*}{ Household owns land } & -0.0351 & -1.20 & 0.0075 & 0.21 & & 0.0015 & 0.0260 \\
\hline & \multicolumn{2}{|c|}{1064} & & & Total Changes & 0.0021 & 0.0142 \\
\hline Obs. & \multirow{2}{*}{\multicolumn{2}{|c|}{$\begin{array}{c}1064 \\
0.0781\end{array}$}} & \multicolumn{2}{|c|}{796} & M. Educ. & -0.0157 & 0.0594 \\
\hline$R^{2}$ & & & \multicolumn{2}{|c|}{0.173} & F. Educ & 0.0013 & -0.0090 \\
\hline$\hat{P}(z<-2)$ & \multicolumn{2}{|c|}{0.1998} & \multicolumn{2}{|c|}{0.2162} & Health Amen. & 0.0062 & 0.0166 \\
\hline
\end{tabular}


Table 11: Oaxaca Decomposition, Height-for-Age, Rural North-East

\begin{tabular}{|c|c|c|c|c|c|c|c|}
\hline Males & $\beta_{92-93}$ & $t_{92-93}$ & $\beta_{98-99}$ & $t_{98-99}$ & & $\Delta_{X}$ & $\Delta_{\beta}$ \\
\hline Mother literate below middle sch. & -0.0665 & -2.44 & -0.0714 & -3.32 & & -0.0013 & -0.0007 \\
\hline Mother completed middle sch. & -0.0783 & -1.94 & -0.1349 & -4.67 & & -0.0023 & -0.0043 \\
\hline Mother completed at least high school & -0.1577 & -4.29 & -0.2410 & -8 & & -0.0044 & -0.0069 \\
\hline Father has primary education & 0.0254 & 1.08 & -0.0337 & -1.57 & & -0.0012 & -0.0090 \\
\hline Father has secondary education & 0.0092 & 0.41 & -0.0603 & -3.31 & & 0.0002 & -0.0255 \\
\hline Father has higher education & -0.0630 & -1.55 & -0.0511 & -1.8 & & -0.0059 & 0.0018 \\
\hline High birth order (above 3 ) & 0.0484 & 2.87 & -0.0027 & -0.17 & & -0.0019 & -0.0178 \\
\hline Household head is woman & -0.0330 & -1.08 & -0.0044 & -0.13 & & -0.0002 & 0.0015 \\
\hline Muslim & 0.0041 & 0.15 & -0.0118 & -0.5 & & 0.0000 & -0.0022 \\
\hline Other religions & -0.1432 & -4.7 & -0.0731 & -2.09 & & 0.0019 & 0.0028 \\
\hline Health sub-centre in village & -0.0313 & -1.45 & -0.0083 & -0.46 & & -0.0020 & 0.0076 \\
\hline Primary Health Center in village & -0.0262 & -0.75 & 0.0024 & 0.09 & & -0.0010 & 0.0032 \\
\hline Village has no drainage & 0.0465 & 2.3 & -0.0086 & -0.54 & & -0.0017 & -0.0310 \\
\hline Anganwadi in village & -0.0416 & -2.05 & -0.0113 & -0.67 & & -0.0076 & 0.0162 \\
\hline Mahila Mandal in village & 0.0328 & 1.45 & -0.0250 & -1.32 & & -0.0021 & -0.0114 \\
\hline Pharmacy in village & 0.0631 & 2.82 & -0.0035 & -0.17 & & -0.0040 & -0.0142 \\
\hline Fair Price Shop (PDS) in village & -0.0296 & -1.49 & 0.0024 & 0.15 & & -0.0056 & 0.0173 \\
\hline Village is electrified & -0.0347 & -1.51 & -0.0200 & -1.01 & & -0.0019 & 0.0106 \\
\hline \multirow[t]{2}{*}{ Household owns land } & -0.0152 & -0.83 & -0.0216 & -1.3 & & 0.0007 & -0.0043 \\
\hline & & & \multicolumn{2}{|c|}{4866} & Total Changes & -0.0464 & 0.0354 \\
\hline Obs. & \multicolumn{2}{|c|}{4378} & 48 & & M. Educ. & -0.0080 & -0.0119 \\
\hline$R^{2}$ & \multicolumn{2}{|c|}{0.153} & \multicolumn{2}{|c|}{0.1707} & F. Educ & -0.0070 & -0.0327 \\
\hline$\hat{P}(z<-2)$ & \multicolumn{2}{|c|}{0.5293} & \multicolumn{2}{|c|}{0.5183} & Health Amen. & -0.0184 & -0.0295 \\
\hline Females & $\beta_{92-93}$ & $t_{92-93}$ & $\beta_{98-99}$ & $t_{98-99}$ & & $\Delta_{X}$ & $\Delta_{\beta}$ \\
\hline Mother literate below middle sch. & -0.0289 & -1.20 & -0.0654 & -3.05 & & -0.0004 & -0.0051 \\
\hline Mother completed middle sch. & -0.0341 & -0.84 & -0.0926 & -2.63 & & -0.0004 & -0.0033 \\
\hline Mother completed at least high school & -0.1235 & -2.91 & -0.2072 & -6.24 & & -0.0027 & -0.0063 \\
\hline Father has primary education & 0.0148 & 0.69 & -0.0088 & -0.38 & & -0.0005 & -0.0037 \\
\hline Father has secondary education & -0.0223 & -1.07 & -0.0118 & -0.59 & & -0.0005 & 0.0038 \\
\hline Father has higher education & -0.0673 & -1.61 & -0.0479 & -1.71 & & -0.0058 & 0.0028 \\
\hline High birth order (above 3 ) & 0.0349 & 1.89 & 0.0103 & 0.60 & & -0.0012 & -0.0086 \\
\hline Household head is woman & 0.0048 & 0.12 & 0.0143 & 0.41 & & 0.0000 & 0.0005 \\
\hline Muslim & 0.0363 & 1.51 & -0.0243 & -0.98 & & -0.0007 & -0.0077 \\
\hline Other religions & -0.1116 & -3.82 & -0.0797 & -1.91 & & 0.0016 & 0.0012 \\
\hline Health sub-centre in village & -0.0307 & -1.37 & -0.0085 & -0.47 & & -0.0026 & 0.0075 \\
\hline Primary Health Center in village & -0.0159 & -0.48 & -0.0009 & -0.03 & & -0.0005 & 0.0017 \\
\hline Village has no drainage & -0.0111 & -0.54 & -0.0007 & -0.04 & & 0.0005 & 0.0058 \\
\hline Anganwadi in village & 0.0036 & 0.19 & 0.0144 & 0.81 & & 0.0007 & 0.0057 \\
\hline Mahila Mandal in village & -0.0401 & -1.87 & -0.0377 & -1.76 & & 0.0027 & 0.0004 \\
\hline Pharmacy in village & 0.0432 & 1.97 & 0.0025 & 0.11 & & -0.0022 & -0.0090 \\
\hline Fair Price Shop (PDS) in village & 0.0268 & 1.39 & -0.0256 & -1.46 & & 0.0056 & -0.0289 \\
\hline Village is electrified & -0.0468 & -2.10 & -0.0258 & -1.28 & & -0.0028 & 0.0154 \\
\hline \multirow[t]{2}{*}{ Household owns land } & -0.0245 & -1.30 & -0.0185 & -1.06 & & 0.0007 & 0.0040 \\
\hline & & \multirow{2}{*}{\multicolumn{2}{|c|}{4866}} & Total Changes & -0.0076 & 0.0413 \\
\hline Obs. & & & & & M. Educ. & -0.0034 & -0.0147 \\
\hline$R^{2}$ & \multicolumn{2}{|c|}{$\begin{array}{c}4280 \\
0.183\end{array}$} & \multicolumn{2}{|c|}{0.2182} & F. Educ & -0.0068 & 0.0030 \\
\hline$\hat{P}(z<-2)$ & \multicolumn{2}{|c|}{0.5116} & \multicolumn{2}{|c|}{0.5457} & Health Amen. & -0.0014 & 0.0122 \\
\hline
\end{tabular}


Table 12: Oaxaca Decomposition, Height-for-Age, Rural South

\begin{tabular}{|c|c|c|c|c|c|c|c|}
\hline Males & $\beta_{92-93}$ & $t_{92-93}$ & $\beta_{98-99}$ & $t_{98-99}$ & & $\Delta_{X}$ & $\Delta_{\beta}$ \\
\hline Mother literate below middle sch. & -0.0689 & -1.72 & -0.0984 & -1.86 & & 0.0059 & -0.0058 \\
\hline Mother completed middle sch. & -0.1660 & -3.21 & -0.1427 & -2.65 & & -0.0077 & 0.0034 \\
\hline Mother completed at least high school & -0.1717 & -2.79 & -0.1400 & -2.45 & & -0.0203 & 0.0071 \\
\hline Father has primary education & -0.0694 & -1.89 & -0.1325 & -2.41 & & 0.0135 & -0.0102 \\
\hline Father has secondary education & -0.0923 & -2.21 & -0.0766 & -1.65 & & -0.0079 & 0.0064 \\
\hline Father has higher education & -0.0695 & -0.85 & -0.1425 & -2.58 & & -0.0109 & -0.0142 \\
\hline High birth order (above 3 ) & 0.0101 & 0.30 & 0.1382 & 2.69 & & -0.0006 & 0.0229 \\
\hline Household head is woman & -0.0221 & -0.58 & 0.0525 & 0.91 & & 0.0007 & 0.0058 \\
\hline Muslim & 0.0172 & 0.42 & -0.1087 & -2.34 & & 0.0000 & -0.0190 \\
\hline Other religions & 0.1152 & 2.13 & -0.1291 & -1.91 & & -0.0024 & -0.0130 \\
\hline Health sub-centre in village & -0.0485 & -1.24 & -0.0176 & -0.40 & & 0.0027 & 0.0151 \\
\hline Primary Health Center in village & -0.0596 & -1.19 & -0.0130 & -0.27 & & -0.0056 & 0.0149 \\
\hline Village has no drainage & -0.0711 & -2.43 & 0.0156 & 0.41 & & 0.0001 & 0.0330 \\
\hline Anganwadi in village & -0.0713 & -2.21 & 0.0757 & 1.31 & & -0.0143 & 0.1320 \\
\hline Mahila Mandal in village & 0.0331 & 1.04 & 0.0710 & 1.91 & & 0.0012 & 0.0255 \\
\hline Pharmacy in village & 0.0384 & 0.78 & -0.0052 & -0.12 & & 0.0000 & -0.0154 \\
\hline Fair Price Shop (PDS) in village & -0.0658 & -1.87 & -0.0490 & -1.15 & & 0.0037 & 0.0123 \\
\hline Village is electrified & 0.1571 & 0.84 & -0.0822 & -0.70 & & -0.0043 & -0.2294 \\
\hline \multirow[t]{2}{*}{ Household owns land } & 0.0276 & 0.83 & -0.0322 & -0.91 & & -0.0014 & -0.0368 \\
\hline & & & \multirow{2}{*}{\multicolumn{2}{|c|}{872}} & Total Changes & -0.0370 & 0.0166 \\
\hline Obs. & \multicolumn{2}{|c|}{1148} & & & M. Educ. & -0.0222 & 0.0047 \\
\hline$R^{2}$ & \multicolumn{2}{|c|}{0.2089} & \multicolumn{2}{|c|}{0.1785} & F. Educ & -0.0053 & -0.0180 \\
\hline$\hat{P}(z<-2)$ & \multicolumn{2}{|c|}{0.3975} & \multicolumn{2}{|c|}{0.3775} & Health Amen. & -0.0158 & 0.2050 \\
\hline Females & $\beta_{92-93}$ & $\mathrm{t}_{92-93}$ & $\beta_{98-99}$ & $\mathrm{t}_{98-99}$ & & $\Delta_{X}$ & $\Delta_{\beta}$ \\
\hline Mother literate below middle sch. & -0.1287 & -3.12 & -0.1027 & -1.94 & & -0.0022 & 0.0064 \\
\hline Mother completed middle sch. & -0.0573 & -1.09 & -0.1959 & -2.70 & & -0.0016 & -0.0191 \\
\hline Mother completed at least high school & -0.1377 & -2.55 & -0.2334 & -3.45 & & -0.0134 & -0.0194 \\
\hline Father has primary education & -0.0268 & -0.65 & 0.0125 & 0.20 & & 0.0040 & 0.0064 \\
\hline Father has secondary education & -0.0680 & -1.52 & 0.0724 & 1.30 & & -0.0049 & 0.0552 \\
\hline Father has higher education & -0.1149 & -1.77 & 0.0341 & 0.47 & & -0.0153 & 0.0267 \\
\hline High birth order (above 3 ) & 0.0598 & 1.52 & 0.0577 & 1.15 & & -0.0028 & -0.0004 \\
\hline Household head is woman & -0.0692 & -1.54 & -0.0684 & -1.17 & & 0.0012 & 0.0001 \\
\hline Muslim & -0.0183 & -0.43 & -0.0372 & -0.72 & & -0.0003 & -0.0028 \\
\hline Other religions & -0.0085 & -0.15 & -0.1499 & -2.45 & & 0.0002 & -0.0084 \\
\hline Health sub-centre in village & -0.0793 & -2.19 & 0.0041 & 0.09 & & 0.0052 & 0.0394 \\
\hline Primary Health Center in village & -0.0456 & -1.13 & -0.0169 & -0.27 & & -0.0043 & 0.0088 \\
\hline Village has no drainage & 0.0293 & 0.97 & 0.0038 & 0.09 & & 0.0011 & -0.0108 \\
\hline Anganwadi in village & -0.0372 & -1.03 & -0.0010 & -0.01 & & -0.0062 & 0.0324 \\
\hline Mahila Mandal in village & 0.0455 & 1.35 & 0.0015 & 0.03 & & 0.0022 & -0.0297 \\
\hline Pharmacy in village & -0.0020 & -0.04 & -0.0579 & -1.03 & & -0.0001 & -0.0207 \\
\hline Fair Price Shop (PDS) in village & 0.0382 & 0.98 & -0.0107 & -0.22 & & -0.0015 & -0.0368 \\
\hline Village is electrified & -0.0578 & -0.48 & -0.1470 & -1.05 & & 0.0013 & -0.0862 \\
\hline \multirow[t]{2}{*}{ Household owns land } & 0.0181 & 0.51 & -0.0328 & -0.84 & & -0.0007 & -0.0311 \\
\hline & \multirow{2}{*}{\multicolumn{2}{|c|}{1055}} & \multirow{2}{*}{\multicolumn{2}{|c|}{785}} & Total Changes & -0.0421 & 0.0054 \\
\hline Obs. & & & & & M. Educ. & -0.0172 & -0.0321 \\
\hline$R^{2}$ & \multicolumn{2}{|c|}{$\begin{array}{l}1055 \\
0.257\end{array}$} & \multicolumn{2}{|c|}{$\begin{array}{c}785 \\
0.173\end{array}$} & F. Educ & -0.0161 & 0.0882 \\
\hline$\hat{P}(z<-2)$ & \multicolumn{2}{|c|}{0.4346} & \multicolumn{2}{|c|}{0.3980} & Health Amen. & -0.0021 & 0.0195 \\
\hline
\end{tabular}

